\title{
Isokinetic TWC Evaporator Probe: Development of the IKP2 and Performance Testing for the HAIC-HIWC Darwin 2014 and Cayenne-2015 Field Campaigns
}

John W. Strapp

Met Analytics Inc., Aurora, ON, Canada

Lyle E. Lilie

Science Engineering Associates, Inc., Tolland, Conneticut

Thomas P. Ratvasky

Glenn Research Center, Cleveland, Ohio

Craig R. Davison

National Research Council of Canada, Ottawa, ON, Canada

Christopher J. Dumont

FAA William J. Hughes Technical Center, Atlantic City, New Jersey 


\section{NASA STI Program . . . in Profile}

Since its founding, NASA has been dedicated to the advancement of aeronautics and space science. The NASA Scientific and Technical Information (STI) Program plays a key part in helping NASA maintain this important role.

The NASA STI Program operates under the auspices of the Agency Chief Information Officer. It collects, organizes, provides for archiving, and disseminates NASA's STI. The NASA STI Program provides access to the NASA Technical Report Server-Registered (NTRS Reg) and NASA Technical Report ServerPublic (NTRS) thus providing one of the largest collections of aeronautical and space science STI in the world. Results are published in both non-NASA channels and by NASA in the NASA STI Report Series, which includes the following report types:

- TECHNICAL PUBLICATION. Reports of completed research or a major significant phase of research that present the results of NASA programs and include extensive data or theoretical analysis. Includes compilations of significant scientific and technical data and information deemed to be of continuing reference value. NASA counter-part of peer-reviewed formal professional papers, but has less stringent limitations on manuscript length and extent of graphic presentations.

- TECHNICAL MEMORANDUM. Scientific and technical findings that are preliminary or of specialized interest, e.g., "quick-release" reports, working papers, and bibliographies that contain minimal annotation. Does not contain extensive analysis.
- CONTRACTOR REPORT. Scientific and technical findings by NASA-sponsored contractors and grantees.

- CONFERENCE PUBLICATION. Collected papers from scientific and technical conferences, symposia, seminars, or other meetings sponsored or co-sponsored by NASA.

- SPECIAL PUBLICATION. Scientific, technical, or historical information from NASA programs, projects, and missions, often concerned with subjects having substantial public interest.

- TECHNICAL TRANSLATION. Englishlanguage translations of foreign scientific and technical material pertinent to NASA's mission.

For more information about the NASA STI program, see the following:

- Access the NASA STI program home page at http://www.sti.nasa.gov

- E-mail your question to help@sti.nasa.gov

- $\quad$ Fax your question to the NASA STI Information Desk at 757-864-6500

- Telephone the NASA STI Information Desk at 757-864-9658

- Write to:

NASA STI Program

Mail Stop 148

NASA Langley Research Center Hampton, VA 23681-2199 


\section{Isokinetic TWC Evaporator Probe: Development of the IKP2 and Performance Testing for the HAIC-HIWC Darwin 2014 and Cayenne-2015 Field Campaigns}

John W. Strapp

Met Analytics Inc., Aurora, ON, Canada

Lyle E. Lilie

Science Engineering Associates, Inc., Tolland, Conneticut

Thomas P. Ratvasky

Glenn Research Center, Cleveland, Ohio

Craig R. Davison

National Research Council of Canada, Ottawa, ON, Canada

Christopher J. Dumont

FAA William J. Hughes Technical Center, Atlantic City, New Jersey

Prepared for the

8th Atmospheric and Space Environments Conference

sponsored by AIAA

Washington, D.C., June 13-17, 2016

National Aeronautics and

Space Administration

Glenn Research Center

Cleveland, Ohio 44135 


\section{Acknowledgments}

Funding to support this project was provided by the Federal Aviation Administration, the NASA Aviation Safety Program, Environment Canada, and Transport Canada. The authors thank the staff of Science Engineering Associates, the NASA Icing Research Tunnel, the Cox and Co. Icing Wind Tunnel, the NRC Research Altitude Test Facility (RATFac), and the NRC M7 test cell 5 for their contributions to this work. Mr. Dan Bouley, Mr. Chris Sivo, Mr. Tim Breithaupt, and Mr. Charles Landreville provided important technical support to the work. The support from the SAFIRE Falcon-20 aircraft team in developing the IKP2 downsizing plan for the Falcon-20, and in the collection of any Falcon-20 data described in this article, is also greatly appreciated.

Trade names and trademarks are used in this report for identification only. Their usage does not constitute an official endorsement, either expressed or implied, by the National Aeronautics and Space Administration.

Level of Review: This material has been technically reviewed by technical management.

Available from

NASA STI Program

Mail Stop 148

NASA Langley Research Center

Hampton, VA 23681-2199
National Technical Information Service 5285 Port Royal Road Springfield, VA 22161 703-605-6000

This report is available in electronic form at http://www.sti.nasa.gov/ and http://ntrs.nasa.gov/ 


\title{
Isokinetic TWC Evaporator Probe: Development of the IKP2 and Performance Testing for the HAIC-HIWC Darwin 2014 and Cayenne-2015 Field Campaigns
}

\author{
John W. Strapp \\ Met Analytics Inc. \\ Aurora, ON, Canada L4G 4Y1 \\ Lyle E. Lilie \\ Science Engineering Associates, Inc. \\ Tolland, Conneticut 06084 \\ Thomas P. Ratvasky \\ National Aeronautics and Space Administration \\ Glenn Research Center \\ Cleveland, Ohio 44135 \\ Craig R. Davison \\ National Research Council of Canada \\ Ottawa, ON, Canada K1A 0R6 \\ Christopher J. Dumont \\ FAA William J. Hughes Technical Center \\ Atlantic City, New Jersey 08405
}

\begin{abstract}
A new Isokinetic Total Water Content Evaporator (IKP2) was downsized from a prototype instrument, specifically to make airborne measurements of hydrometeor total water content (TWC) in deep tropical convective clouds to assess the new ice crystal Appendix D icing envelope. The probe underwent numerous laboratory and wind tunnel investigations to ensure reliable operation under the difficult high altitude/speed/TWC conditions under which other TWC instruments have been known to either fail, or have unknown performance characteristics. The article tracks the testing and modifications of the IKP2 probe to ensure its readiness for three flight campaigns in 2014 and 2015. Comparisons are made between the IKP2 and the NASA Icing Research Tunnel reference values in liquid conditions, and to an exploratory technique estimating ice water content from a bulk ice capture cylinder method in glaciated conditions. These comparisons suggest that the initial target of 20 percent accuracy in TWC has been achieved and likely exceeded for tested TWC values in excess of about $0.5 \mathrm{gm}^{-3}$. Uncertainties in the ice water content reference method have been identified. Complications are introduced in the necessary subtraction of an independently measured background water vapour concentration, errors of which are small at the colder flight temperatures, but increase rapidly with increasing temperature, and ultimately limit the practical use of the instrument in a tropical convective atmosphere to conditions colder than about $0{ }^{\circ} \mathrm{C}$. A companion article in this conference traces the accuracy of the components of the IKP2 to derive estimated system accuracy.
\end{abstract}




\section{Nomenclature}

$\begin{array}{ll}\text { IKP1 } & \text { isokinetic probe, prototype } \\ \text { IKP2-1 } & \text { isokinetic probe, second generation, serial no. 1 } \\ \text { IKP2-2 } & \text { isokinetic probe, second generation, serial no. 2 } \\ \text { TWC } & \text { total water content } \\ \text { LWC } & \text { liquid water content } \\ \text { BWV } & \text { background water vapour } \\ \text { MMD } & \text { median mass diameter } \\ \text { MVD } & \text { median volume diameter } \\ \text { ICC } & \text { ice capture cylinder }\end{array}$

\section{Introduction}

In 2004, the Engine Harmonization Working Group (EHWG), a multi-agency group comprised of aircraft and engine manufacturers, regulating authorities, and government agencies involved in aircraft icing research, was tasked to examine the effects of supercooled large droplet and mixed-phase/glaciated icing on aircraft engines. In the process of this work, the group concluded that over 100 engine powerloss events were most likely due to flight in mixed-phase/glaciated conditions in or near deep convective clouds, and that most of these events occurred outside Appendix C conditions. Early investigations of the meteorological conditions conducive to engine events (Refs. 1 and 2) suggested that the aircraft were flying through areas of high ice water content (IWC) cloud, and that supercooled liquid water content (LWC) was not required (Ref. 2). Little was known about the microphysical properties of these clouds, or the mechanism for ice accretion in warm engines in a glaciated cloud (ice particles with no LWC). The EHWG proposed a technical plan to perform research to increase understanding of the phenomenon, including improvement of instrumentation to measure the high IWC environment, flight measurements to characterize the type of clouds that caused engine events, improvement of ground simulation facilities, and physical studies of ice accretion and improvement of ice accretion models. The EHWG also proposed a new ice crystal envelope (Ref. 3) based on information from engine events, theoretical limits for TWC in rising updrafts, and extensive measurements of deep convection made in the 1950s by the Royal Aircraft Establishment (Ref. 4). The Federal Aviation Administration (FAA) and the European Aviation Safety Agency (EASA) both incorporated the new ice crystal envelope (FAA Part 33 Appendix D, EASA CS-25 Appendix P) in rules that became effective on 5 Jan. 2015 and 12 Mar. 2015, respectively (Refs. 5 and 6). The FAA concurred with the EHWG Technical Plan that further measurements were required to assess the TWC levels and ice particle sizes contained in Appendix D, and would consider changes to the law once airborne measurements were complete if appropriate. Since the discovery of ice crystal icing induced engine events, it is now known that this type of icing is also responsible for failures of aircraft air data probes (Ref. 7).

In 2006, the High Ice Water Content (HIWC) Project was initiated in North America and Australia to prepare instrumentation and modify an aircraft for a proposed flight program in deep convective clouds out of Darwin, Australia. A science plan (Ref. 8) was developed in concert with the EHWG, and its successor the Engine Icing Working Group (EIWG), to support the assessment of the new Appendix D, and to perform fundamental research into the properties of deep convection. In 2012, due to difficulties in completing the aircraft installation, the HIWC project broadened an existing collaboration with the High Altitude Ice Crystals (HAIC) project (Ref. 9) which had developed similar objectives, naming the collaborative effort the HAIC-HIWC Project. The HAIC-HIWC project has completed two flight programs to date: one in Darwin, Australia in Jan.-Mar. 2014, and a second out of Cayenne, French Guiana in May 2015. The HIWC project has completed a third project out of Florida in Aug. 2015. The HAIC-HIWC projects have been performed using the Service des Avions Français Instrumentés pour la 
Recherche en Environnement (SAFIRE) Falcon-20 research aircraft as the primary high-altitude aircraft. The National Research Council of Canada Convair-580 aircraft was also used in the Cayenne-2015 project, concentrating on measurements at the $-10{ }^{\circ} \mathrm{C}$ level. The NASA DC- 8 aircraft was used for the Florida HIWC RADAR flight campaign. All three aircraft were highly instrumented for cloud microphysics measurements, and included identical Isokinetic TWC Evaporator probes, as will be described below.

This article describes aspects of the development and performance testing of the new Isokinetic TWC Evaporator instrument to measure the hydrometeor total water content (TWC) in a high speed/altitude/ TWC environment, stressing its second generation version developed specifically for the constraints of the Falcon-20 aircraft. A companion article examines the equations used in calculation of TWC, and provides analytical and numerical derivations of system accuracy, estimated at about 2 to 3 percent for TWC greater than $0.5 \mathrm{gm}^{-3}$ and temperatures colder than $-29^{\circ} \mathrm{C}$ (Ref. 10). Errors increase with temperature due to increases in background water vapour, as will be shown below.

\section{The Prototype Airborne Isokinetic TWC Evaporator (IKP1)}

Airborne instrumentation for the in-situ measurements of clouds has undergone a long period of development and improvement since their earliest versions of hot-wire probes, bulk hydrometeor collectors, particle impactors etc. in the 1940s and 1950s. In the 1970s, the introduction of digital spectrometers marked a revolution in cloud measurements. One of the most significant advances was the recording of images of cloud particles for computer analysis, thereby providing a significant improvement in the measurement of mixed-phase clouds. While these technologies have been continuously improved since, there still remain significant shortcomings in cloud measurements, particularly in the separation of liquid and ice components in mixed-phase, and in the accurate measurement of ice particles smaller than about $100 \mu \mathrm{m}$. Estimations of the mass spectrum of ice particles rely on mass-diameter relationships (or equivalent) derived from limited ground collections of ice crystals, which vary according to particle type, and have an unknown transferability to particles high in the atmosphere such as those collected during the recent flight programs. For this reason, estimates of ice mass from the integration of particle size distributions from imaging spectrometers remains problematic and with poorly understood errors. One study, for example, showed about a factor of 2 difference inferred mass-diameter relationships of general cloud versus tropical convective clouds (Ref. 11). Hot-wires have also been used to estimate cloud TWC and LWC, and special sensors with capture volumes have been shown to have a higher collection efficiency for IWC than cylindrical sensors (Ref. 12). Using a combination of capture volume TWC sensors and cylindrical sensors more sensitive to LWC than IWC, and knowing the efficiencies of each sensor for ice and water, it has been shown that one should be able to derive the separate LWC and TWC components. However, high speed video has shown that a significant fraction of ice particles are ejected from TWC sensors (Refs. 13 to 15), and the efficiency of ice capture by TWC sensors can be lower than 50 percent (Refs. 14 to 17). Furthermore, the characteristics of this ice capture efficiency versus airspeed, pressure, particle type, etc. have not been characterized. Another class of cloud TWC instrument is the commonly called evaporator. As opposed to the hot-wire, which is clearly also an evaporator, this class of instrument ingests cloud particles into an inlet, melts and evaporates the particles, and then measures the total humidity of the background + evaporated liquid water drops and ice particles. Several of these instruments have been developed in the research community since the 1960s, although none have been widely used. Some instruments have been developed primarily for the measurement of high-altitude lowIWC clouds, e.g., References 18 to 20, and are unsuitable for very high IWC measurements for a variety of reasons. The counter flow virtual impactor (Ref. 20), and its commercial variant the Droplet Measurement Technologies Cloud Spectrometer and Impactor (CSI), both ingest cloud particles into a dry counter-flow, and have provided promising measurements at high altitude and high speed in the low to intermediate IWC range, but have been observed to saturate at IWC values lower than expected for the current flight campaigns. 
The primary objective of the Appendix D assessment flight campaigns is to make in-situ TWC measurements of tropical deep convective clouds up to $10 \mathrm{gm}^{-3}$, at temperatures between -10 and $-50{ }^{\circ} \mathrm{C}$ and true airspeeds up to about $200 \mathrm{~ms}^{-1}$, with an accuracy of better than 20 percent. The EHWG examined the available TWC instruments, and concluded that although they were often adequate for the research environments in which they were being used, their accuracy in the high IWC environment could not be adequately quantified, and/or their operation in the harsh environment could not be assured. Accuracy could not be guaranteed to better than a factor of 2. Consequently, it was decided to develop a new instrument specifically for the high IWC environment. The initial design decisions resulted from discussions between Environment and Climate Change Canada (ECCC, formerly Environment Canada) and the National Research Council (NRC) of Canada. Given what appeared to be complex issues remaining to resolve in hot-wire and spectrometer based TWC estimation, and after a brief examination of some new instrument concepts for TWC estimation, it was decided to develop a humidity-based evaporator system optimized for high IWC measurements. It was concluded that such a system would represent the closest measurement to a 'first principles' bulk measurement whose uncertainties could be determined and quantified. The use of an isokinetic inlet system would minimize the uncertainties of collection and retention efficiency over a wide range of ice particle sizes, which is the primary uncertainty in hot-wire TWC estimates. The primary measurement of the system, the increase in the humidity due to evaporated hydrometeors, would be a simple bulk measurement directly proportional to the TWC, if the mass flow through the instrument were accurately measured.

The basic design of the system was established by ECCC and NRC, after which the detailed design, engineering and fabrication of the device was accomplished by NRC with assistance from Science Engineering Associates (SEA). Details of the design and initial testing of the prototype have been described elsewhere (Refs. 21 to 25). Briefly, air and hydrometeors enter a $10 \mathrm{~mm}$ inlet, and then travel through an unobstructed spiral evaporator section. Informal information from previous evaporator designs indicated that saturation might be a primary issue under high IWC conditions, so the flow path was designed to be open, avoiding the use of screens or other potential blockages or accumulation points. Calculations predicted that insignificant mass would exit the probe unevaporated: particles larger than $\sim 25 \mu \mathrm{m}$ would melt and evaporate on the walls of evaporator spiral flow path, and those smaller would have sufficient residence time to evaporate even without striking a wall (Ref. 25). In order to achieve near-isokinetic flow through the inlet, the flow through the probe was measured using an orifice plate, and controlled with a butterfly valve to match the geometric flow through the inlet (the desired flow). The humidity of the air after the evaporator section was measured with a tunable diode laser (TDL) humidity measurement system. Hydrometeor TWC was deduced by subtracting an independent measurement of background humidity from the IKP1 TDL total (hydrometeor + background) humidity. The IKP1 was developed and underwent initial wind tunnel testing, with the intention of using this probe for the primary TWC measurements in the upcoming flight program. As described in the next section, the requirement to move to a smaller aircraft ultimately determined that the development and testing would shift to a smaller probe, the subject of this article.

\section{Development of the IKP2 Instrument}

Initial intentions were to use the IKP1 prototype instrument for the earlier mentioned flight campaigns on a mid-size Gulfstream G-II jet that was being instrumented for the NASA Glenn Research Center. In the fall of 2012, circumstances required the cancellation of the development of this aircraft, and new plans were made to focus the primary TWC measurements on the SAFIRE Falcon-20 aircraft, which had been a second aircraft but now became the sole aircraft for the Darwin campaign. The IKP1 was quickly found to exceed the power, weight, and size constraints of the Falcon-20, and the aircraft would require a significant wing re-wiring effort to accommodate the IKP1. The solution was to downsize the probe through re-design, and manufacture a new "IKP2" probe to operate with existing wing wiring, while maintaining the basic original design. The overall project was led by SEA, and funded by the FAA and NASA. The NRC provided the downsized evaporator and flow path. SEA was responsible for all 
TABLE 1.-PROPERTIES OF THE PROTOTYPE IKP1 AND THE SECOND

GENERATION IKP2, ILLUSTRATING THE MODIFICATION EFFORT TO

DOWNSIZE FOR USE ON THE SAFIRE FALCON-20 AIRCRAFT

\begin{tabular}{|c|c|c|c|}
\hline & IKP1 & $\begin{array}{c}\text { Falcon-20 } \\
\text { target }\end{array}$ & IKP2 \\
\hline Weight (kg) & 57 & 30 & ${ }^{\mathrm{b}} 29$ \\
\hline $\begin{array}{c}\text { Est. drag at } \\
200 \mathrm{~m} / \mathrm{s} \text { IAS (N) }\end{array}$ & 691 & 400 & ${ }^{\mathrm{a}} 458$ \\
\hline Est. Max. Power (Kw) & 4.5 & 2.5 & 2.5 \\
\hline Wing interface & $\begin{array}{c}\text { Same as } \\
\text { IKP2 }\end{array}$ & NATO mount & $\begin{array}{c}\text { NATO } \\
\text { mount compatible }\end{array}$ \\
\hline $\begin{array}{c}\text { Wing wiring } \\
\text { (\# of wires) }\end{array}$ & 72 & 48 & 24 \\
\hline
\end{tabular}

${ }^{a}$ Acceptable to SAFIRE

bWith "gondola" adapter

other tasks, including changing the hygrometer, repackaging the probe, providing various control systems, power and data systems, probe integration and delivery, and providing lead support on the installation of the probe on the aircraft. Table 1 shows the major changes in downsizing the IKP1 to the IKP2 probe. Guidelines for target values are also provided when applicable.

The initial challenge was the approximate 45 percent power reduction required to meet the power limits of the Falcon-20 while maintaining a critical cloud instrument configuration. This was accomplished by reducing the inlet diameter from $10 \mathrm{~mm}$ to about $7 \mathrm{~mm}$, thereby reducing the isokinetic airflow and hydrometeor catch through the circular inlet by about a factor of 2 . Weight and drag reductions were met by physically reducing the size of the probe, and incorporating an extended rear cone. The original probe was housed in a cylindrical canister similar to that used for the DMT CSI. Its diameter and length were about 22.5 and $185 \mathrm{~cm}$ respectively, and there was an extended strut between the cylinder and the aircraft attachment point for additional necessary components. The downsized probe is housed in a similar but smaller layout (diameter $=17.8 \mathrm{~cm}$, length $=156 \mathrm{~cm}$ ), more similar to an extended Particle Measuring Systems canister with an interfacing strut. Drag was reduced by about 34 percent by this downsizing and by integrating the extended rear cone. The original design incorporated a large number of wire pairs for probe diagnostics and control. The wiring was greatly reduced by incorporating a new on-board microprocessor to manage these data internally, and transferring equivalent data to the cabin-mounted data acquisition system via serial transfers. Figure 1 shows a drawing of the IKP2, and a picture of the probe mounted under the wing of on the SAFIRE Falcon-20 research aircraft. The probe is mounted with the leading edge of the inlet well forward of the leading edge of the wing and clear of the aircraft fuselage. Another three underwing mounting locations (e.g., see two in background of picture) are used for particle spectrometers and a SEA hot-wire Robust probe.

The IKP2 also incorporated a different humidity measurement system. The TDL used in the IKP1 was a one-of-a-kind system for which support was no longer available, and several reliability and accuracy issues had already been flagged for follow-up. The development team concluded that due to the relatively remote locations expected for future flight campaigns and the requirement for spares, it would be necessary to adopt only a mature, commercially available and fully supported hygrometer for the IKP2. The team concluded that the LICOR-840A was the only commercially available solution that would not require a repackaging to fit within the space constraints of the new probe.

Time was of the essence in the development of the IKP2. The schedule was driven by the need to have a fully operational probe for a flight program with a fixed time window in Darwin, Australia in Jan. 2014. The need for the IKP2 was first identified in Dec. 2012. The agreements on the design and the go-ahead from the funding agencies were secured by Feb. 2013, when the effort was officially launched. The development, fabrication, and initial bench testing was completed by Jun. 2013. Initial wind tunnel testing was completed in Jun. and Jul. of 2013, and the probe was sent to France for pre-installation inspection in Sep. 2013. Bench testing of a new evaporator was completed by NRC by Sep. of 2013 to remedy a saturation problem observed in the Jun. and Jul. wind tunnel testing. The probe was sent back to the USA, and integrated with the new evaporator in Oct. 2013. Two further wind tunnel tests were 

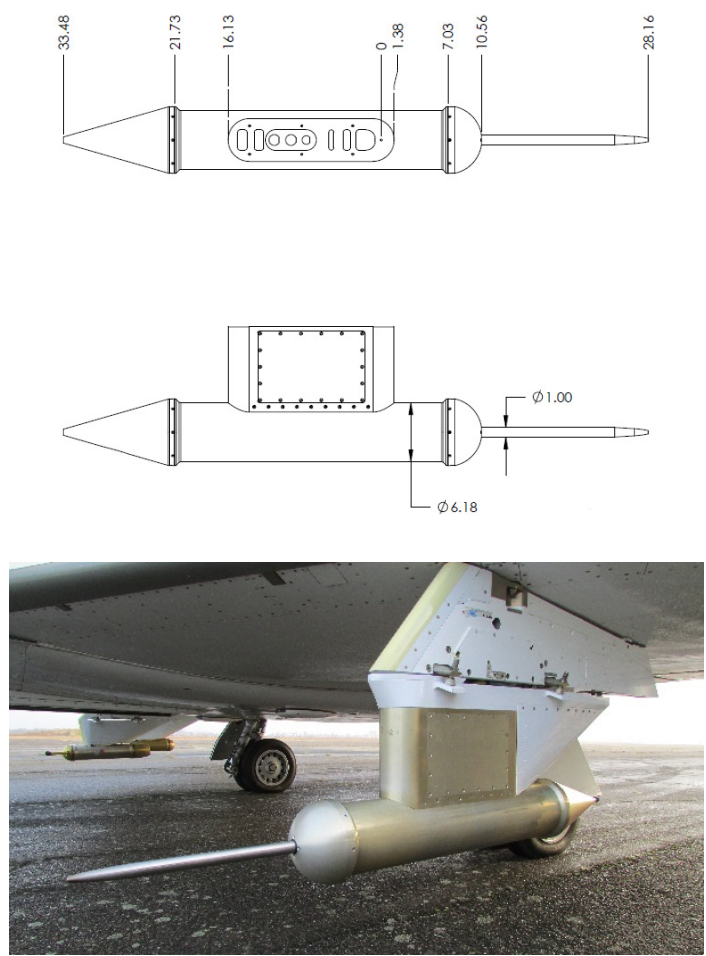

Figure 1.-Top: drawing of the IKP2. Dimensions are in inches, and bottom: picture of the IKP2 mounted on the CNRS Falcon-20 research aircraft.

performed in Oct. and Nov. 2013 to ensure overall proper operation, and to get initial estimates of probe accuracy, and then the probe was shipped back to France in Dec. 2013 for flight testing prior to the Jan. 2014 Darwin flight campaign. The probe was then operated successfully for a $72 \mathrm{hr}$ flight program in Darwin from 16 Jan. to 18 Feb. 2014. The probe was designed and fabricated, underwent four separate wind tunnel testing entries and an evaporator redesign, was flight tested and declared ready for flight within 12 months of the launch of the effort.

\section{Performance Testing of the IKP2 Instrument}

The IKP2 has undergone extensive bench, wind tunnel, and flight testing from the completion of its initial fabrication to the present. A second nearly identical copy has been manufactured to support parallel NASA objectives. In the following sections, the results from a series of wind tunnel tests focused on characterizing the performance of the probe will be examined. Results on the probe performance will be summarized in this section, and comparisons to other measurements of LWC and IWC will be summarized in Section V.

Table 2 contains a summary of these wind tunnel tests and their primary objectives. Note that there were a total of seven wind tunnel test entries at four different tunnels with different specializations. The IKP2 was tested under both LWC conditions and high IWC conditions, including tests at altitude. Some tests represent repeats of earlier tests after probe modifications. 
TABLE 2.-SUMMARY OF WIND TUNNEL TESTING PERFORMED ON THE IKP2-1 AND IKP2-2 PROBES

[IKP2-2 is a nearly identical copy of IKP2-1. Both are downsized versions of the original IKP1 prototype. The test entries are numbered in the first column for more efficient reference in the text.]

\begin{tabular}{|c|c|c|c|c|c|}
\hline Wind Tunnel & Dates & IKP2-1 & IKP2-2 & Comments & Primary Objectives and nominal conditions \\
\hline $\begin{array}{l}\text { 1. Cox and } \\
\text { Co. Icing } \\
\text { Wind } \\
\text { Tunnel } \\
\text { (Ref. 26) }\end{array}$ & $\begin{array}{l}\text { 9-Jul-13 to } \\
\text { 12-Jul-13, } \\
\text { 29-Jul-13 to } \\
\text { 2-Aug-13 }\end{array}$ & $\mathrm{x}$ & & $\begin{array}{l}\text { - First performance } \\
\text { testing of IKP } 2 \text { probe }\end{array}$ & $\begin{array}{l}\text { - General operation, structural integrity, isokinetic } \\
\text { flow, de-icing, saturation } \\
\text { - Testing of ice capture cylinder technology } \\
\text { - } 80 \mathrm{~m} / \mathrm{s} \text {, ambient pressure for airspeed } \\
\text { - LWC: } 0.5-2.5 \mathrm{gm}^{-3}, \mathrm{MVD} 15-50 \mu \mathrm{m} \\
\text { - IWC: } 0.5-5 \mathrm{gm}^{-3}, \mathrm{MMD} \sim 200 \mu \mathrm{m} ; \mathrm{IWC} \text { to } \\
\sim 10 \mathrm{gm}^{-3} \text { in recirculating frozen LWC sprays }\end{array}$ \\
\hline $\begin{array}{l}\text { 2. NASA } \\
\text { Icing } \\
\text { Research } \\
\text { Tunnel } \\
\text { (Ref. 27) }\end{array}$ & $\begin{array}{l}\text { 17-Jul-13 to } \\
18-J u l-13\end{array}$ & $\mathrm{x}$ & & $\begin{array}{l}\text { - First high-speed testing } \\
\text { of IKP2 probe }\end{array}$ & $\begin{array}{l}\text { - General operation, structural integrity, isokinetic } \\
\text { flow, de-icing, saturation } \\
\text { - First LWC comparisons } \\
\text { - } 77-154 \mathrm{~ms}^{-1} \text {, ambient pressure for airspeed } \\
\text { - LWC: } 0.5-3.2 \mathrm{gm}^{-3}, \text { MVD } 20-199 \mu \mathrm{m} \\
\text { - IWC: to } 10 \mathrm{gm}^{-3} \text { in recirculating frozen LWC } \\
\text { sprays, MMD unknown but likely low }\end{array}$ \\
\hline $\begin{array}{l}\text { 3. NRC } \\
\text { Research } \\
\text { Altitude } \\
\text { Test } \\
\text { Facility } \\
\text { (RATFac) } \\
\text { (Refs. 28 } \\
\text { and 29) }\end{array}$ & $\begin{array}{l}12-\text { Nov-13 to } \\
13-\text { Nov-13 }\end{array}$ & $\mathrm{x}$ & & $\begin{array}{l}\text { - First tests at altitude } \\
\text { - After evaporator } \\
\text { redesign to mitigate } \\
\text { saturation } \\
\text { - New more precise inlet } \\
\text { tip } \\
\text { - Testing at very high } \\
\text { IWC }\end{array}$ & $\begin{array}{l}\text { - General operation, saturation at very high IWC, } \\
\text { performance at altitude } \\
\text { - Test the recent modifications insulating the LICOR } \\
\text { inlet sample lines and adding an active heater to the } \\
\text { LICOR } \\
\text { - IWC comparisons and particle loss before } \\
\text { evaporation } \\
\text { - All tests with glaciated conditions, MMD = } 55 \mu \mathrm{m} \\
\text { - } 192 \mathrm{~ms}^{-1} \mathrm{TAS}, 208 \mathrm{mb},-42 \mathrm{C} \mathrm{SAT}, 4-12 \mathrm{gm}^{-3} \mathrm{IWC} \\
\text { - } 173 \mathrm{~ms}^{-1} \mathrm{TAS}, 301 \mathrm{mb},-30 \mathrm{C} \mathrm{SAT}, 4-10 \mathrm{gm}^{-3} \mathrm{IWC} \\
\text { - } 147 \mathrm{~ms}^{-1} \mathrm{TAS}, 437 \mathrm{mb},-20 \mathrm{C} \mathrm{SAT}, 4-10 \mathrm{gm}^{-3} \mathrm{IWC} \\
\text { - } 96 \mathrm{~ms}^{-1} \mathrm{TAS}, 776 \mathrm{mb},-30 \mathrm{C} \mathrm{SAT}, 4-10 \mathrm{gm}^{-3} \mathrm{IWC}\end{array}$ \\
\hline $\begin{array}{l}\text { 4. NASA } \\
\text { Icing } \\
\text { Research } \\
\text { Tunnel } \\
\end{array}$ & $\begin{array}{l}12-\text { Nov-13 to } \\
13-\text { Nov-13 }\end{array}$ & $\mathrm{x}$ & & $\begin{array}{l}\text { - Re-check of probe in } \\
\text { LWC and glaciated } \\
\text { conditions before flight } \\
\text { campaign }\end{array}$ & $\begin{array}{l}\text { - General operation, structural integrity, isokinetic } \\
\text { flow, de-icing, saturation } \\
\text { - New LWC comparisons with improved inlet tip }\end{array}$ \\
\hline $\begin{array}{l}\text { 5. Cox and } \\
\text { Co. Icing } \\
\text { Wind } \\
\text { Tunnel } \\
\end{array}$ & $\begin{array}{l}\text { 30-Nov-14 to } \\
\text { 5-Dec-14 }\end{array}$ & $\mathrm{x}$ & $\mathrm{x}$ & $\begin{array}{l}\text { - First performance } \\
\text { testing of IKP2-2 probe } \\
\text { - New flow enhancer }\end{array}$ & $\begin{array}{l}\text { - General operation, structural integrity, isokinetic } \\
\text { flow with flow enhancer, de-icing, saturation } \\
\text { (IKP2-2) } \\
\text { - Further testing of ice capture cylinder technology }\end{array}$ \\
\hline $\begin{array}{l}\text { 6. NASA } \\
\text { Icing } \\
\text { Research } \\
\text { Tunnel } \\
\end{array}$ & $\begin{array}{l}\text { 15-Dec-14 to } \\
17-\text { Dec-14 }\end{array}$ & $\mathrm{x}$ & $\mathrm{x}$ & $\begin{array}{l}\text { - Carefully organized } \\
\text { with NASA IRT staff to } \\
\text { optimize LWC } \\
\text { calibration accuracy } \\
\end{array}$ & $\begin{array}{l}\text { - Primary LWC comparisons to tunnel reference } \\
\text { values } \\
\text { - Background humidity inlet testing }\end{array}$ \\
\hline $\begin{array}{l}\text { 7. NRC M7 } \\
\text { Test Cell } 5 \\
\text { (M7TC5) } \\
\text { (Ref. 23) }\end{array}$ & $\begin{array}{l}\text { 11-Jan-16 to } \\
\text { 22-Jan-16 }\end{array}$ & $\mathrm{x}$ & & & $\begin{array}{l}\text { - Primary IWC comparisons to bulk ice capture } \\
\text { cylinder estimates } \\
\text { - Background humidity inlet testing }\end{array}$ \\
\hline
\end{tabular}

\section{A. Evaporator Saturation Testing and Modifications}

One of the primary probe performance concerns was whether the probe could keep up with the flux of hydrometeors and avoid accumulation of moisture in the flow path, which in severe cases can result in a saturation of the signal, and a long hysteresis after exit from cloud conditions. Such behavior is usually associated with ice particles, and has been previously observed with the DMT CSI probe, an evaporator probe with some similarities to the IKP2. CSI saturation had been personally observed by the authors during flights by Environment Canada and NRC in lake effect storms containing high IWC. Severe saturation can greatly deteriorate measurements for periods of tens of minutes and require exiting cloud to clear the flow path of accumulated water before measurements can resume.

The earliest such testing of the IKP2 (test 1, Table 2) quickly identified a saturation issue at measured IWC values of about $10 \mathrm{gm}^{-3}$, at or below the tunnel maximum airspeed of $90 \mathrm{~ms}^{-1}$. The saturation was not difficult to reproduce, and was suspected to have resulted from insufficient flow velocity through the evaporator. Earlier work showed that the Stokes parameter best describes the probe's capacity to move any accumulated liquid through the evaporator to prevent pooling that would lead to saturation. In order 

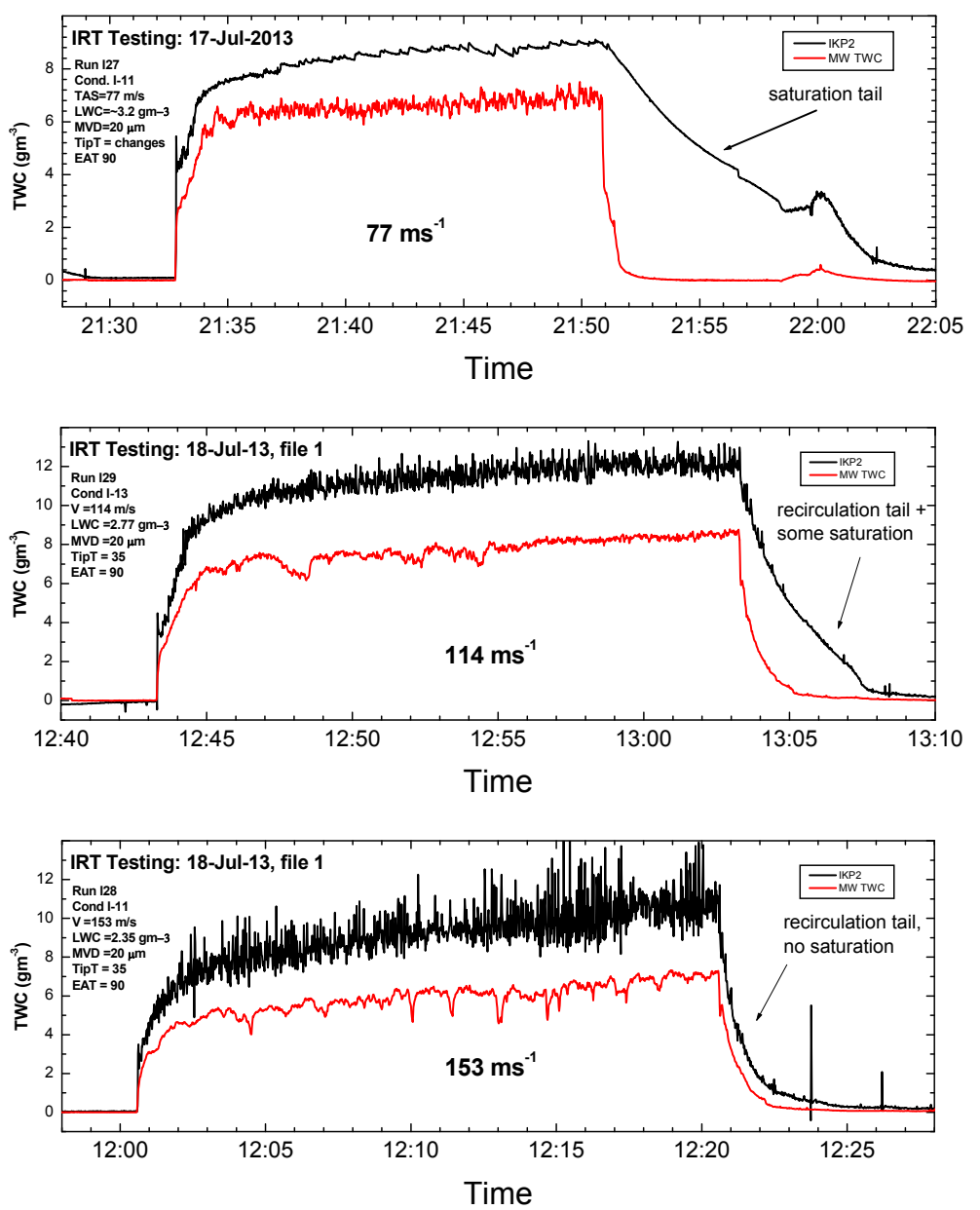

Figure 2.-Saturation tests of IKP-2 before evaporator rebuild, at the NASA IRT (test 2, Table 2): $77 \mathrm{~ms}^{-1}$ (top), $114 \mathrm{~ms}^{-1}$ (middle), and $153 \mathrm{~ms}^{-1}$ (bottom). The capacity of the evaporator to move hydrometeors through the flow path is most similar to high altitude flight conditions for the middle panel (see text).

Recirculation of ice in the tunnel leads to increasing concentrations with time.

to simulate the Stokes parameter of the evaporator's flow at flight conditions of $200 \mathrm{mb}(20 \mathrm{KPa})$ and $-40{ }^{\circ} \mathrm{C}$, an appropriate test in the ground based wind tunnels was at about $114 \mathrm{~ms}^{-1}$ and $-30{ }^{\circ} \mathrm{C} \mathrm{SAT}$. At the NASA IRT (test 2, Table 2), it was possible to test to higher speeds, and although the tunnel did not have an ice shaver to produce simulated ice clouds, it was possible to produce very high IWC frozen sprays at cold temperature by reducing the water temperatures to the nozzles. Figure 2 shows an example of saturation runs at 77,114, and $153 \mathrm{~ms}^{-1}$, all for the same nozzle spray settings, and thus approximately the same initial flux of LWC in the tunnel. The IWC values reached during each of the three runs vary somewhat, and far exceed the values expected from the LWC injection alone, due to the continual recirculation and accumulation of ice particles in the tunnel. The run at $153 \mathrm{~ms}^{-1}$ displays a normal response with no significant saturation. The IKP2 signal (black line) is lively. The values rise with time, probably due to ice recirculation around the closed loop tunnel. The SEA multi-element TWC hot-wire probe (red line), uncorrected for ice capture efficiency, and with some damping in the probe's response, mimics the response of the IKP2, albeit at lower values due to its lower ice collection and retention efficiency. After the spray is turned off, the concentrations of both probes do not immediately drop to zero, but instead drop gradually as ice continues to recirculate in the tunnel. During this time the SEA probe measures an approximate constant fraction of the IKP2 TWC, a good indication that the IKP2 has had no hydrometeor buildup in the flow system. The run at $77 \mathrm{~ms}^{-1}$ (top panel) exhibits a strong IKP2 
saturation response. The probe signal is much less lively. After the spray is turned off, the signal does not immediately drop at the same rate as the SEA probe in the recirculation tail, but takes more than 13 min to reach pre-spray values. This is a classic saturation response, and there are cases from the Cox and Co. testing (test 1, Table 2) where even stronger symptoms were observed. The middle panel of Figure 2 shows the response at the airspeed that best represents the Stokes parameter appropriate for the flow through the evaporator at target flight conditions. Note that the response is somewhere in between that of the saturating (top panel) and non-saturating (bottom panel) cases, and there is indication of an extended recovery of the IKP2 relative to the SEA probe after the spray has been turned off. In particular, by 13:06 the SEA probe has nearly reached its pre-spray values, while the IKP2 is still measuring of the order of $3 \mathrm{gm}^{-3}$. These cases do not provide a quantitative description of the effect of airspeed on saturation because the flux of particles achieved in each case was different and difficult to predict in real-time. For example, based on the raw IWC values measured by the SEA probe, the flux of particles (IWC $\mathrm{x}$ airspeed) achieved in the $153 \mathrm{~ms}^{-1}$ run was more than two times that of the $77 \mathrm{~ms}^{-1}$ run. However, it does point out that the higher airspeed run was not saturating even under twice the particle flux. The fact that saturation occurred at all at the $114 \mathrm{~ms}^{-1}$ airspeed, with evaporator flow characteristics closest to the expected flight conditions, was a cause for concern to the IKP2 development team. In August 2013, the NRC expended great efforts to diagnose the source of the saturation. The problem was identified, and remedied through design changes to the evaporator. It was initially validated with a nylon prototype version allowing visual confirmation that pooling had been eliminated under relevant flight conditions.

A new evaporator was fabricated, and was ready for integration into the IKP2 for further testing in Oct. 2013.

The next set of wind tunnel tests with the new evaporator were conducted at the NRC RATFac (test 3, Table 2). Note that these tests were performed in glaciated conditions under realistic flight airspeeds, pressures, and temperatures. Ice cloud was produced using a grinder which provided particles with MMDs of approximately $55 \mu \mathrm{m}$. The most challenging test for the evaporator is shown in Figure 3 . Note that the nominal IWC for this run was $12 \mathrm{gm}^{-3}$, but was based on early estimates from a hot-wire and tunnel mapping, and was considered exploratory. The actual momentary maximum values reached by the IKP2 were in excess of $20 \mathrm{gm}^{-3}$, with an average values from 12:04 to 12:13 of about $15.5 \mathrm{gm}^{-3}$. The IKP2 signal was very lively, and when the ice grinder was turned off (vertical green line on plot), the values returned to pre-cloud values relatively quickly, and on a time frame similar to the SEA multielement hot-wire probe (red line, only exposed to the cloud at the beginning and end of the test run). Three additional post-evaporator redesign saturation runs were performed during the November 2013

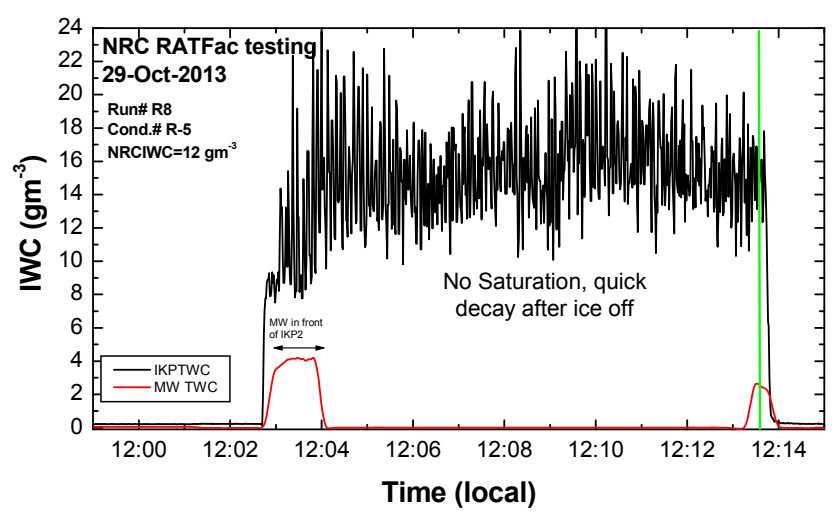

Figure 3.-Highest IWC test, from the NRC RATFac wind tunnel testing (test 4, Table 2) in October 2013, after evaporator rebuild. Test conditions were $-42{ }^{\circ} \mathrm{C} \mathrm{SAT}, 192 \mathrm{~ms}^{-1}$ true airspeed, and $208 \mathrm{mb}$ static pressure. The SEA multi-element probe is only temporarily within the ice plume at the beginning and end of the test run. Vertical green line marks the approximate time of turning off the ice grinder. 
IRT wind tunnel measurements (test 4, Table 2). The runs all used the same nozzle settings as the 3 runs in Figure 2, but for airspeeds of 77, 103, and $155 \mathrm{~ms}^{-1}$ (note $103 \mathrm{~ms}^{-1}$ rather than $114 \mathrm{~ms}^{-1}$ ). No saturation was observed during any of these runs. A repeat of the $103 \mathrm{~ms}^{-1}$ run was performed in December 2014 (test 6, Table 2), and again no saturation was observed.

These tests convinced the IKP2 development team that the evaporator redesign had successfully mitigated the saturation problem described in Figure 2, and any remaining accumulation of particles in the flow path was now of minor significance. The tests reveal that the evaporator continued to be effective through December 2014 and presumably beyond. Continual monitoring for saturation is now also accomplished through the use of the field calibration cart described in Section V.A. Saturation was not observed under normal flight operation of the IKP2 during the HAIC-HIWC and HIWC RADAR flight programs, although IWC values rarely reached above about $4 \mathrm{gm}^{-3}$.

\section{B. Other Saturation Testing and Modifications}

The IKP2 LICOR-840 humidity measurement system is housed in the strut above the main cylindrical canister that houses the flow path, and an airline of approximately $15 \mathrm{~cm}$ length is used to transport air from the flow path into the heated LICOR measurement cell. The IKP2 development team recognized that a temperature gradient inside the probe from the flow path to the strut could be expected at cold flightaltitude temperatures, and that cooling of this airline below the dewpoint temperature of the flow path air could result in condensation on its inner wall, resulting in another potential source of probe saturation. Consequently, the airline was insulated, and airline wall temperature measurements were made as a diagnostic. In early tests (tests 1-2, Table 2) the airline temperature had not lowered sufficiently and saturation was not observed. However, during pre-testing at the NRC RATFac (test 4, Table 2), it became apparent that condensation might be expected. Further insulation was added to the air line, and an active heater was added to the interior volume of the LICOR just prior to the first day of the tests. At the outset, the probe was deliberately operated without the additional LICOR heater, and condensation was not observed in the very first series of runs below a nominal IWC of $8 \mathrm{gm}^{-3}$. Test conditions were approximately $-43{ }^{\circ} \mathrm{C} \mathrm{SAT}, 200 \mathrm{~ms}^{-1}$ true airspeed and $200 \mathrm{mb}(20 \mathrm{KPa})$ static pressure. However, on the next run at a nominal IWC of $10 \mathrm{gm}^{-3}$ (Fig. 4, top panel), saturation due to apparent condensation was
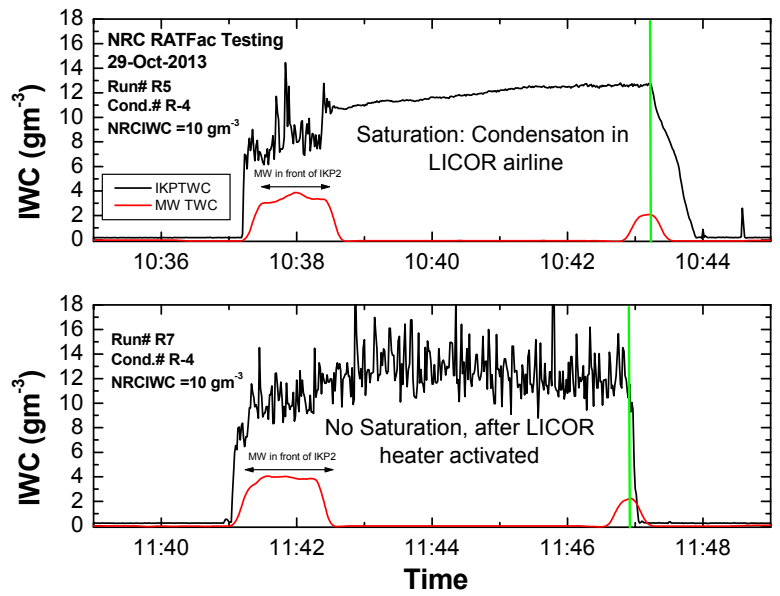

Figure 4.- Testing of condensation in the air line from the flow-path to the LICOR in the IKP2, resulting in saturation (upper panel), and results with additional LICOR heater (lower panel). Data were collected at the NRC RATFac wind tunnel (test 4, Table 2) under realistic flight conditions (approximately $200 \mathrm{~ms}^{-1}$ true airspeed, $200 \mathrm{mb}$ static pressure, and $-43^{\circ} \mathrm{C}$ SAT). Operation of SEA multi-element probe, and time of spray-off are as described in Figure 3. 
observed starting at about 10:38:45. On this run the flow path dewpoint was within a few degrees of the outside wall temperature of the air line, and may have been colder still inside the LICOR enclosure itself. The active heater was turned on, and the run was repeated (Fig. 4, lower panel). The heater raised the airline temperature by about $10{ }^{\circ} \mathrm{C}$, safely above the flow path dewpoint temperature. In this run, and in all subsequent runs (all with the active heater on), there were no further symptoms of condensationsaturation. It was concluded that there was sufficient margin with the added insulation and active heaters to handle IWCs up to $10 \mathrm{gm}^{-3}$ and beyond under realistic flight conditions during the upcoming flight programs, and that the monitoring of the airline temperature and flow path dewpoint would provide an adequate diagnostic for assessing whether further heater and/or insulation was required. In the 3 flight campaigns to date, there have been no occurrences of airline condensation-saturation.

\section{Particle Flow-Through}

In order to provide the most accurate estimate of the hydrometeor TWC, the IKP2 must melt and evaporate all particles within its flow path, and not eject un-evaporated particles out the airflow exhaust. The evaluation of the efficacy of the probe in this regard is not straightforward, and currently relies on calculations and indirect evidence.

It is believed that the calculations are strong and convincing. These calculations predict that particles larger than $\sim 25 \mu \mathrm{m}$ will strike the evaporator wall, which has a temperature similar to that of a hot-wire TWC sensor, within $7 \mathrm{~cm}$ of the first of 10 spiral turns (Ref. 24). Particles impacting the walls would have enhanced residence time and heat transfer for melting and evaporation. Particle smaller than $25 \mu \mathrm{m}$ are calculated to have sufficient time in the flow path without hitting the wall to melt and evaporate, although it is likely that only the smallest of such particles could make it through 10 spiral turns without impaction. The air temperature in the flow path is controlled so that air in the spiral section is always warmer than $80^{\circ} \mathrm{C}$. The calculations therefore show that it is unlikely that significant mass of cloud particles would exit the probe unevaporated.

If there were un-evaporated particles exiting the probe, one might speculate that the fraction of such particles would increase with increasing IWC, as the difference between the flow path vapour pressure and its saturation value decreased under higher IWC loadings. The best data we have to test this hypothesis comes from the NRC RATFac (test 4, Table 2), which were collected under realistic flight conditions, and included the highest IWC values of all the testing summarized in Table 2. For a given airspeed and static pressure, it is intuitively expected that the distribution of ice in the tunnel would be independent of ice delivery rate, and that a linear relationship between the measured IWC and delivery rate should be found for locations within the main ice plume. Such results from the RATFac testing are shown in Figure 5, for the three primary atmospheric flight levels/airspeeds tested in the tunnel (see test 4, Table 2 for details). The ice delivery rate is displayed in the $\mathrm{lb} / \mathrm{hr}$ units used by the RATFac operators. A linear best fit line is shown for each atmospheric condition. The variations between these lines in relatively small, and may be due to small shifts in the spatial pattern of ice distribution under the different atmospheric conditions. Note that the measured IKP2 TWC is quite linear with respect to ice delivery rate for each atmospheric condition, even up to measured IWCs in excess of $15 \mathrm{gm}^{-3}$. There is no drop-off at higher rates that might be attributed as to an increasing un-evaporated fraction. Un-evaporated particles are therefore only present if they are at a constant mass fraction independent of IWC. Further indirect support that unevaporated particles are at most a minor effect is contained in Section V, where IKP2 measurements of LWC and IWC are compared to those from other measurements considered to have relatively small uncertainties. 


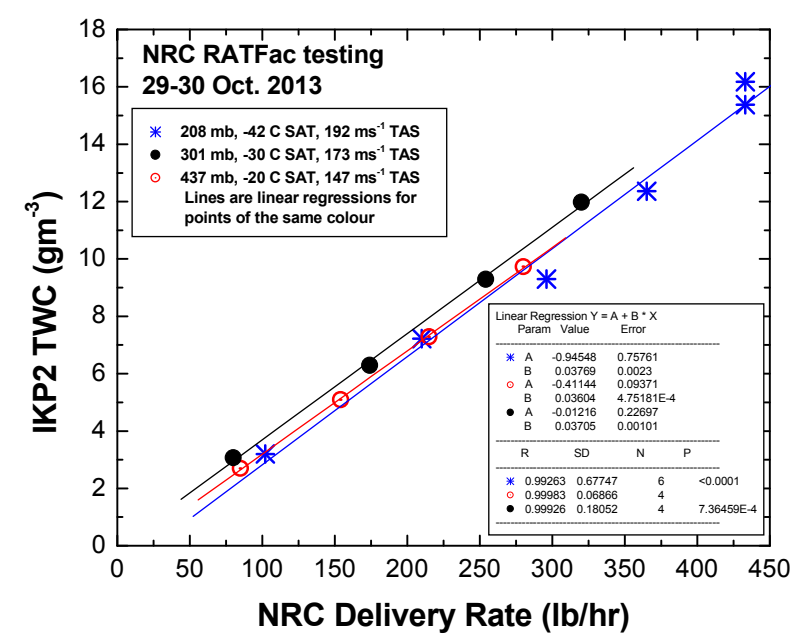

Figure 5.-Measured IKP2 IWC as a function of rate of ice delivered to the tunnel, at the NRC RATFac (test 4, Table 2). Tests are for three atmospheric conditions and airspeeds similar to those expected in tropical flight campaigns.

\section{Isokinetic Flow Performance}

The IKP2 was designed to generate a slightly super-isokinetic flow by using an expanded exhaust diameter to recover the inlet total pressure. Super-isokinetic flow is throttled to isokinetic values in realtime using automatic probe controls. The desired isokinetic flow conditions are estimated by calculating the geometric mass-flow sweep-out of the circular cross section of the inlet. The actual mass flow is measured in the flow path after the evaporator section using a calibrated orifice plate. The measured and desired flows are then compared in real time, and the flow is modified using the butterfly valve to match the desired flow. The ratio of the measured flow to the desired flow is called here the 'isokinetic factor' (IKF), and is an indicator of the proximity to isokinetic flow, a value of 1 being ideal. In reality, the influence of the body of the probe itself also affects whether the probe is isokinetic for a given particle size, and matching the desired and measured flow does not result in perfect isokineticity for all particle sizes. This is only an issue for the smallest particles, and efficiency estimates have been provided (Ref. 10). However, as applied for the current flight programs where almost all the data are from ice clouds, less than 10 percent of the mass is typically smaller than $100 \mu \mathrm{m}$ (Ref. 30). Under such conditions, the particle can be considered ballistic, and the primary advantage of isokinetic sampling is to ensure that the retention efficiency of particles is essentially unity, as opposed to other designs such as hot-wires where a significant fraction of particles have been shown to be ejected (Refs. 13 to 15).

When the butterfly valve is deliberately held fully open, the IKF is a measure of the flow margin above the isokinetic value. Initial estimates in wind tunnels revealed a comfortable margin, but during the first flight program values sometimes dropped to sub-isokinetic values between 0.90-1.0 for extended periods. The lower values were in part due to higher localized pressure under the wing compared to free stream conditions. Although TWC values could be corrected using the IKF values (Ref. 10), maintaining an isokinetic flow remained the more desirable option, so the NRC proposed a flow enhancer extension to the exhaust to increase flow. Figure 6 shows measurements of the IKF at the NASA IRT in December 2014 (test 6, Table 2) for IKP2-2, with and without the flow enhancing exhaust extension. At $100 \mathrm{~ms}^{-1}$, for example, the valve- open IKF value increases from about 1.15 to 1.20 , about a 4.3 percent increase in flow margin. The increase in the margin decreased with true airspeed. Thus the flow enhancer provided a modest improvement under the conditions tested at the IRT. Figure 7 shows flight measurements of the IKF value with the flow restriction valve deliberately left full open, enabling the assessment of the flow 


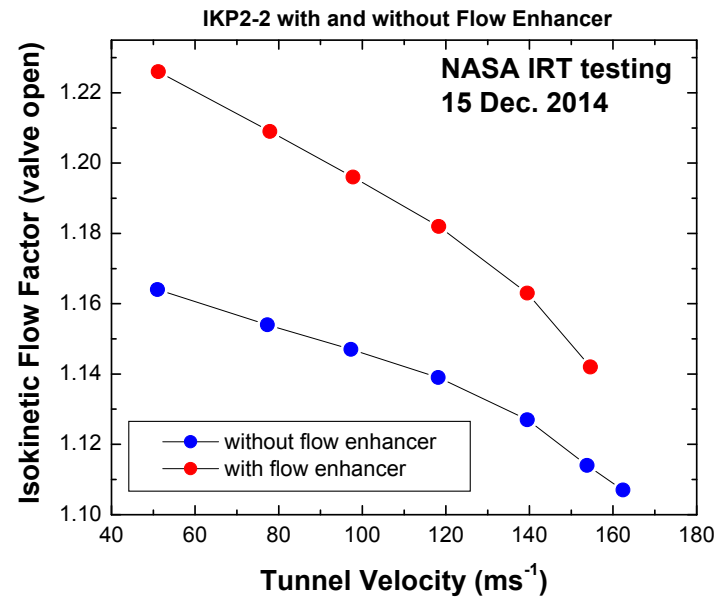

Figure 6.-Measurements of the isokinetic flow factor (IKF), the ratio of maximum flow (valve open) to isokinetic flow, with and without a flow enhancer extension at the exhaust of the IKP2. Results are for IKP2-2.

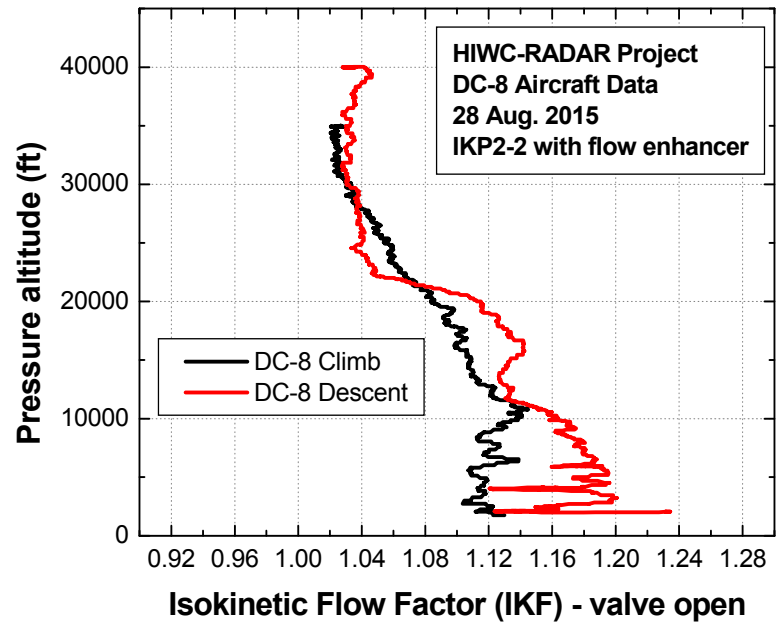

Figure 7.-Measurements of the IKP2-2 isokinetic flow factor (IKF) during climb and descent on the NASA DC-8 aircraft during the HIWC-RADAR project. The IKP2-2 was mounted under the wing near the wingtip. During this flight, the IKP2-2 flow restriction valve was held fully open, and the flow enhancer was installed.

margin over the isokinetic value in a warm tropical environment. The data are 11-sec centered- average values from the initial climb and final descent profiles of the flight. First, one can see that IKF decreases with height. Although values similar to the IRT experiments of Figure 6 are observed in the lower atmosphere, at the top of the profiles ( 35000 to $40000 \mathrm{ft}, 10670$ to $12195 \mathrm{~m}$ ), the isokinetic flow margin is only 2 to 4 percent. Second, it is evident that there are differences between the climb and descent profiles, perhaps due to aircraft attitude or other flight parameters. Throughout the use of the IKP2 in 3 flight programs, it has been evident that IKF values have been somewhat sensitive to aircraft maneuvers such as climbs, airspeed increases, and turns, and airplane configuration such as flap setting. For example, even at high altitude, the flow margin elsewhere in the flight of Figure 7 temporarily increased to +1.20 after initiation of a decent, or decreased to 0.97 during a turn (not shown). In general, the controlled IKF value in straight and level flight varies between about 0.90 and 1.05, and most departures from unity are either momentary, perhaps due to turbulence or large changes in TWC (the desired flow is a weak function of hydrometeor TWC), or responses to flight maneuvers. If and when IKF values depart from unity, the TWC can usually be corrected with a simple IKF scale adjustment (Ref. 10).

\section{E. Tip Redesign}

During early wind tunnel tests, comparisons of the IKP2 LWC and IWC were made to other reference values. In the course of this work, the IKP2 probe tip was carefully examined. Any diameter measurement uncertainties or shape irregularities could potentially inject significant errors into the LWC and/or IWC calculations. The top photograph in Figure 8 shows the original IKP2-1 inlet, as used in tests 1-2, Table 2. The IKP2 development team was concerned about the roundness of the leading edge of the inlet and some irregularity in its shape, and unsure as to what fraction of particles striking the leading edge would deflect to the interior of the inlet versus away from the inlet. This introduced a potential uncertainty in the probe's sample volume, and may have contributed to the larger than expected early discrepancies observed when comparing TWCs to other instruments. The probe tip was reworked (Fig. 8, bottom photograph) to machine a sharp bevel at the leading edge of the inlet that would deflect particles striking its leading edge away from its entrance. In addition, the entrance was carefully machined to provide a circular diameter that could be accurately measured. Although there were other additional changes made 


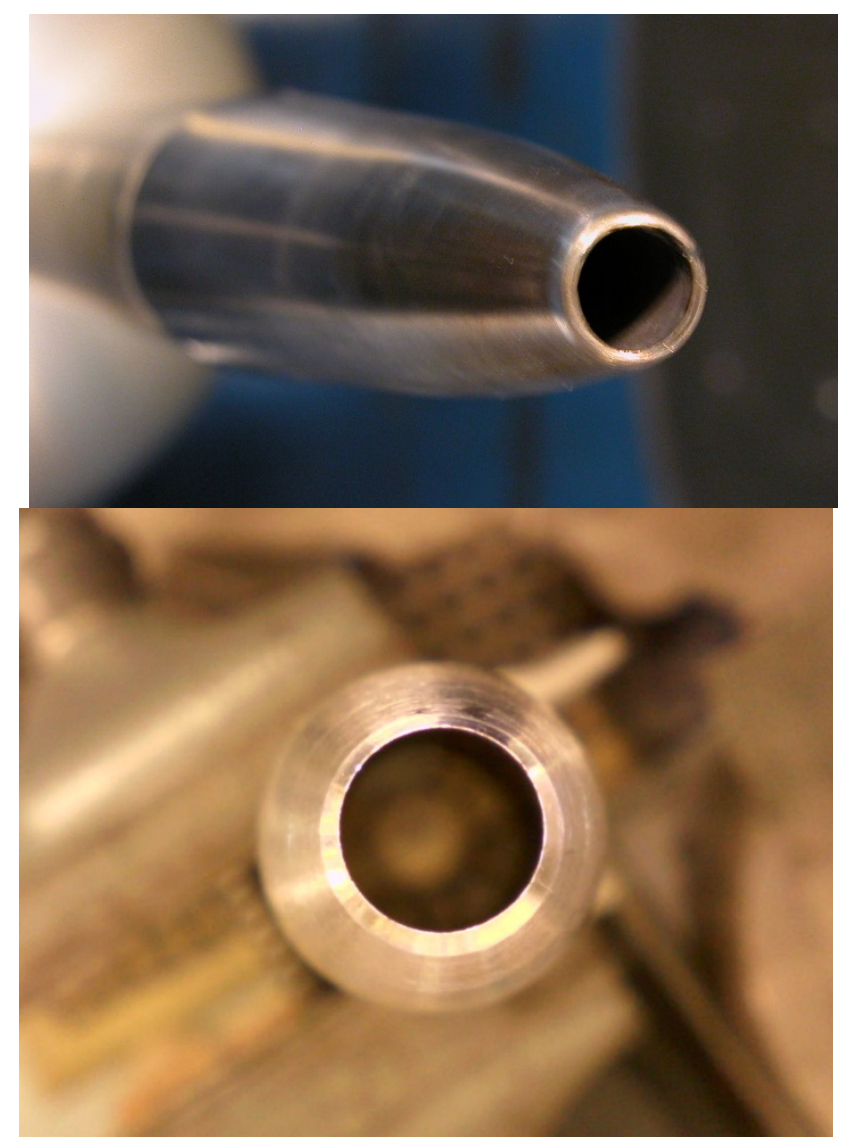

Figure 8.-The top photograph shows the inlet of IKP2-1 during wind tunnel tests $1-2$, Table 2 . Note the somewhat rounded leading edge and irregularity of the shape of the tip on the lower tight inside circumference. The lower photograph shows the reshaped inlet used in tests 3-7, with the sharply beveled leading edge that more precisely defines the swept out sample area.

to the probe and processing (e.g., a new evaporator), the development team suspects that the tip redesign was at least partially responsible for the considerable improvement in LWC and IWC comparisons after the redesign. Post-modification comparisons will be summarized in Section V.

\section{F. Probe De-icing}

Although the strut and front dome of the IKP2 are not deiced, special efforts have been made in the design and testing of the deicing of the probe inlet tip. The inlet diameter is relatively small (about $7 \mathrm{~mm}$ ) and must be kept free of accreted ice during encounters with supercooled liquid cloud that may reach several $\mathrm{gm}^{-3}$ in deep tropical convection. The IKP2 maintains the average inlet tip temperature at an adjustable constant value. The first assessment of deicing performance after the tip redesign was performed with IKP2-1 at the NASA IRT in Nov. 2013 (test 4, Table 2). Although no dedicated deicing tests were performed, it was determined by trial and error that a tip temperature of $40{ }^{\circ} \mathrm{C}$ was required to keep the inlet deiced under the test conditions, and this temperature has been used thereafter in most testing and flight operations. The Nov. 2013 IRT testing focused on comparisons of the IKP2 LWC to the tunnel reference values. In the course of this work the probe was exposed to airspeeds of up to $155 \mathrm{~ms}^{-1}$ at LWCs up to $2.3 \mathrm{gm}^{-3}$ and TATs of about $-7{ }^{\circ} \mathrm{C}$, in a series of constant LWC exposures lasting 4 min. Inlet deicing was effective for these tests. The next relevant deicing tests were performed at the 
NASA IRT in Dec. 2014 (test 6, Table 2). Again, the tests focused on LWC comparisons to the tunnel reference, which included a series of 3 min exposures at $-10{ }^{\circ} \mathrm{C}$ TAT at a variety of airspeeds, LWCs, and MVDs, and during which the inlet deicing was always effective. The most challenging of these from a de-icing perspective was a 3-min exposure to a measured $3.4 \mathrm{gm}^{-3}$ at $-10.4{ }^{\circ} \mathrm{C}$ TAT, $-18.1{ }^{\circ} \mathrm{C} \mathrm{SAT}$, and $125 \mathrm{~ms}^{-1}$ TAS. The dry convective heat loss at the tip was about $520 \mathrm{~W}$, increasing only by about $80 \mathrm{~W}$ when the LWC was added. During flight projects, the typical convective heat losses for IKP2-1 at -10 , -30 , and $-40{ }^{\circ} \mathrm{C}$ were about 310,390 , and $410 \mathrm{~W}$, well below the values experienced in the wind tunnel. Since there is a maximum of about $900 \mathrm{~W}$ available for tip heat, there is plenty of margin above convective heating requirements, especially given the relatively small amount added by the LWC exposure. However, it is not known whether simply maintaining a $40{ }^{\circ} \mathrm{C}$ average tip temperature will be sufficient to keep the tip clear of ice at very high water fluxes, given the possibility of temperature irregularities within the sharply beveled tip. What is known from our tests is that the tip remained ice free in the wind tunnel at dry convective heat loss rates higher than flight, and with an LWC impact flux corresponding to a $\mathrm{LWC}$ of $3.4 \mathrm{gm}^{-3}$ at $125 \mathrm{~ms}^{-1}$. Scaling the latter to the flight velocities at $-10,-30$, and $-40{ }^{\circ} \mathrm{C}$, the same flux would be experienced at LWC conditions of about $2.6,2.4$, and $2.3 \mathrm{gm}^{-3}$ respectively, and the 3 min exposure time would correspond to 15.8, 17.0, and $18.2 \mathrm{~nm}$ distance exposures respectively. Comparing these values to Part 25, Section C25.1 Appendix C icing envelopes (Ref. 31), the test exposures are about three times higher than the worst Appendix $\mathrm{C}$ values for continuous icing at the standard $17.4 \mathrm{~nm}$ distance scale, and are in fact 80 to 90 percent of the worst-case intermittent maxima at $2.6 \mathrm{~nm}\left(2.9 \mathrm{gm}^{-3}\right.$ at $15 \mu \mathrm{m}$ effective diameter $)$, and which are only provided to a maximum of $5.2 \mathrm{~nm}$.

The IKP2-2 was also successfully tested for a single 15-min exposure at a measured $4.9 \mathrm{gm}^{-3}$, $-12.8 \mathrm{SAT}$, and $74.9 \mathrm{~ms}^{-1}$. Following the same logic as above, these results scaled to flight airspeeds at $-10,-30$, and $-40{ }^{\circ} \mathrm{C}$ were $2.3,2.1$, and $2.0 \mathrm{gm}^{-3}$, respectively, but correspond to much longer exposure distances of 86,94 , and $100 \mathrm{~nm}$, respectively.

In summary, we have tested the IKP2 in LWC values similar to the worst-case $2.6 \mathrm{~nm}$ Appendix C intermittent maxima but at distance scales well past those for continuous maxima. It is highly likely that the IKP2 would remain ice free to higher LWCs, and there is still power available to go to a significantly higher tip temperature and presumably higher LWCs.

\section{G. Removal of Background Humidity}

The IKP2 measures the sum of the hydrometeor TWC plus the background humidity, and calculation of the hydrometeor TWC requires the subtraction of an independently acquired background water vapour (BWV) measurement. The accurate measurement of BWV has proven to be a surprisingly challenging problem, and is not a fully resolved issue for all applications. The dominant factors complicating the measurement can vary from wind tunnels to flight measurements. Only a cursory examination of the issue is presented in this article, with some discussion about the effect on the accuracy of airborne and wind tunnel measurements, and suggestions for future improvements. The topics discussed below include the increasing importance of background humidity as ambient temperature increases, offsets in the LICOR840A hygrometers and mitigation, the effect of improper time synchronization of the IKP2 and BWV signals and/or unintended damping of one of the signals, and the effect of the inlet choice on contamination of BWV by hydrometeor ingestion or by adiabatic temperature rises in its vicinity. The development of the most accurate inlet system is still a work in progress, and current limitations still require manual treatment of data with sometimes subjective decisions as how to best deal with suspected BWV uncertainty. 
TABLE 3.-MAGNITUDE OF BACKGROUND VAPOUR (BWV) CONCENTRATIONS IN WATER AND ICE SATURATED CLOUDS, CONVERTED TO $\mathrm{gm}^{-3}$ FOR AN AVERAGE DARWIN (JAN.-MAR.) SOUNDING

\begin{tabular}{|c|c|c|}
\cline { 2 - 3 } \multicolumn{1}{c|}{} & \multicolumn{2}{|c|}{ Background vapour concentrations } \\
\hline $\mathrm{T}(\mathrm{C})$ & $\begin{array}{c}\text { Water } \\
\text { saturation } \\
\left(\mathrm{gm}^{-3}\right)\end{array}$ & $\begin{array}{c}\text { Ice } \\
\text { saturation } \\
\left(\mathrm{gm}^{-3}\right)\end{array}$ \\
\hline-10 & 2.37 & 2.15 \\
\hline-20 & 1.08 & 0.89 \\
\hline-30 & 0.45 & 0.34 \\
\hline-40 & 0.18 & 0.12 \\
\hline-50 & ---- & 0.04 \\
\hline
\end{tabular}

\section{Magnitude of Expected Background Humidity}

Fortunately, for a great deal of the flight measurements for which this probe was developed, the atmospheric temperatures are colder than $-30^{\circ} \mathrm{C}$, and the $\mathrm{BWV}$ is low relative to the expected high IWC values. Relative humidity in cloud is expected to be regulated by the evaporation of water and ice particles. In the broad tops of the tropical MCS studied in the flight campaigns for which this instrument was designed, clouds are generally found to have IWC values continuously exceeding $0.1 \mathrm{gm}^{-3}$ and reaching up to several $\mathrm{gm}^{-3}$. It is a reasonable first assumption in such clouds that the in-cloud relative humidity is between ice and water saturation, although it is also clear that situations exist where the relative humidity may be sub saturated with respect to ice (Ref. 32), particularly in lower altitude precipitation areas. Table 3 contains ice and water saturation BWV values, expressed in $\mathrm{gm}^{-3}$, for a Darwin average sounding (January-March). This table provides a first approximation of the magnitude of the BWV levels that are to be subtracted in the IKP2 TWC calculation. At $-10{ }^{\circ} \mathrm{C}$, levels are high, of the same order as the IWC values to be expected in the flight programs, and therefore errors in $\mathrm{BWV}$ subtraction could significantly impact IKP2 TWC accuracy. At $-30{ }^{\circ} \mathrm{C}$, levels are still in excess of $0.3 \mathrm{gm}^{-3}$, but as will be argued later, a more accurate estimate of the BWV uncertainty at $-30{ }^{\circ} \mathrm{C}$ is the difference between the water and ice saturation values, or $0.11 \mathrm{gm}^{-3}$ at this temperature. At $-50{ }^{\circ} \mathrm{C}$, the levels of BWV, and thus the associated TWC errors, are very low. Even very high supersaturations with respect to ice at this temperature would be small relative to the high IWC reading.

\section{Varying Offsets in Background Water Vapour Instruments}

Our experience with the LICOR-840A instruments used both for the IKP2 BWV + hydrometeor and the separate BWV measurements has shown that although the gain of these instruments appears to be quite accurate (e.g., see section V.A), all of the units we have used have been subject to varying baseline offsets. The offsets vary somewhat from day to day, and they vary with pressure. During the wind tunnel test 6 , Table 2, three different LICOR-840A units were exposed to dry nitrogen under varying cell pressures, and the baseline readings, adjusted to be near $0 \mathrm{gm}^{-3}$ at ambient pressure, climbed somewhat linearly to about $0.3 \mathrm{gm}^{-3}$ from 1000 to $500 \mathrm{mb}(100$ to $50 \mathrm{KPa})$. Efforts to measure this pressure effect in flight to date have been unsuccessful. A more practical approach has been to normalize the offsets periodically in post flight processing, in the manner described below.

Out of cloud, the IKP2 and background LICORs should measure the same value, since they are both measuring just BVW in this case. Flight experience has shown that differences between these two measurements are almost always present out of cloud, but the differences tend to change slowly with time if the BWV inlet air lines are uncontaminated. Since the IKP2 TWC is proportional to the difference between the IKP2 and background LICOR measurements, errors due to these out-of-cloud differences can be removed by applying an offset to one or both of the instruments so that they measure the same values out of cloud. This normalization procedure may be applied periodically as appropriate, with offsets in between set points being interpolated. Ideally, offsets would be applied such that both instruments were normalized to an accurate value, such as from an accurate reference humidity instrument, so that accurate 


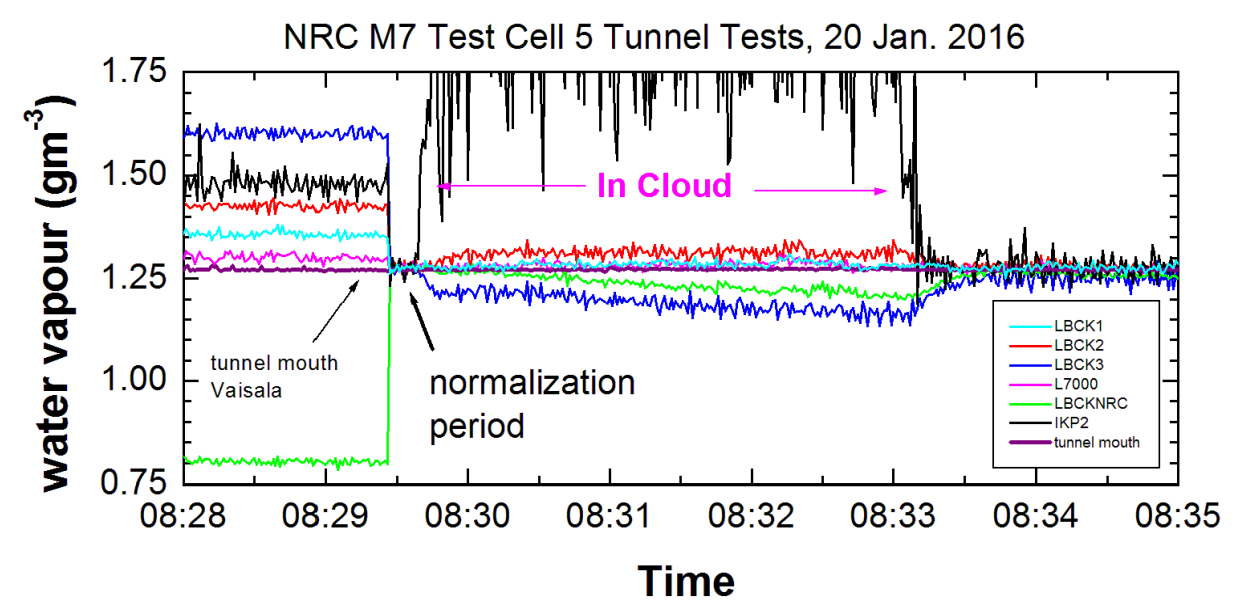

Figure 9.-Example of normalization of IKP2 and background LICOR-840s before the first run of 19 Jan. 2016 at the M7 test cell 5 wind tunnel (test 7, Table 2). An ice cloud was created using shaved ice blocks during the period denoted 'In-Cloud' on the figure. The $y$ axis is truncated at $1.75 \mathrm{gm}^{-3}$ to permit better examination of background water vapour values.

in-cloud humidity could in theory also be measured. However, this is not necessary if the in-cloud BWV measurement is uncontaminated, and only IKP2 TWC measurements are required. An example is shown in Figure 9 from test 7, Table 2, where 5 different background LICORs plus the IKP2 LICOR were tested. BWV was measured independently with a Vaisala sensor at the entrance to the open tunnel. The beginning of this time series contains raw pre-cloud BWV concentrations from all units, including the IKP2, before the first cloud event of the day starting at about 08:29:40. The tunnel mouth Vaisala reading, converted to local BWV using the sample section pressure and temperature, was about $1.25 \mathrm{gm}^{-3}$. Note that the pre-cloud measurements of the various LICORs varied significantly from about 0.80 to $1.60 \mathrm{gm}^{-3}$, and could not be used as-is as BWV measurement for subtraction from the IKP2. During the 15-sec 'normalization period' annotated on Figure 9, just before the start of the ice cloud, offsets are computed from the Vaisala reference measurement, and subtracted from all LICORs to force their agreement. In this case, the offsets applied in Figure 9 were kept constant past the end of this time series. Note that after end of the ice cloud, all of the LICORs return to almost the same pre-cloud value. This provides confidence that the offsets between the LICORs have not changed, and that any one of the BWV LICORs can be considered for use in the subtraction from the IKP2 LICOR to derive the IKP TWC. Note also that the responses of the different LICORs in cloud vary somewhat, reaching a maximum difference of about $0.15 \mathrm{gm}^{-3}$. Which measurement is correct or best suited for IKP2 BWV subtraction? The differences are due to the designs of the inlets, and the positions of the inlets in the tunnel, as will be discussed below. This is an unusual case where other information and deduction has led to the conclusion the air in the tunnel was supersaturated with respect to ice due to the $11^{\circ} \mathrm{C}$ decrease in air static temperature from the tunnel mouth to the sample section, leading to the situation where the ice cloud was a sink for water vapour. The lowest BWV from the center-mounted reverse flow inlet (LBCK3) is likely the most accurate.

\section{Normalization of Water Vapour Measurements in Cloud}

A variation on the above normalization procedure uses in-cloud regions where ice saturation is expected. This method, in addition to removing offsets for the IKP2 TWC calculation, should also provides better estimates of the in-cloud humidity. A similar procedure has been used successfully to normalize LICOR measurements in liquid cloud areas (Ref. 32). Ice saturated regions are chosen by manual inspection and are usually areas of continuous low-moderate IWC cloud where there are no significant updrafts. BWV offsets from ice saturation are calculated for that period, and subtracted to 


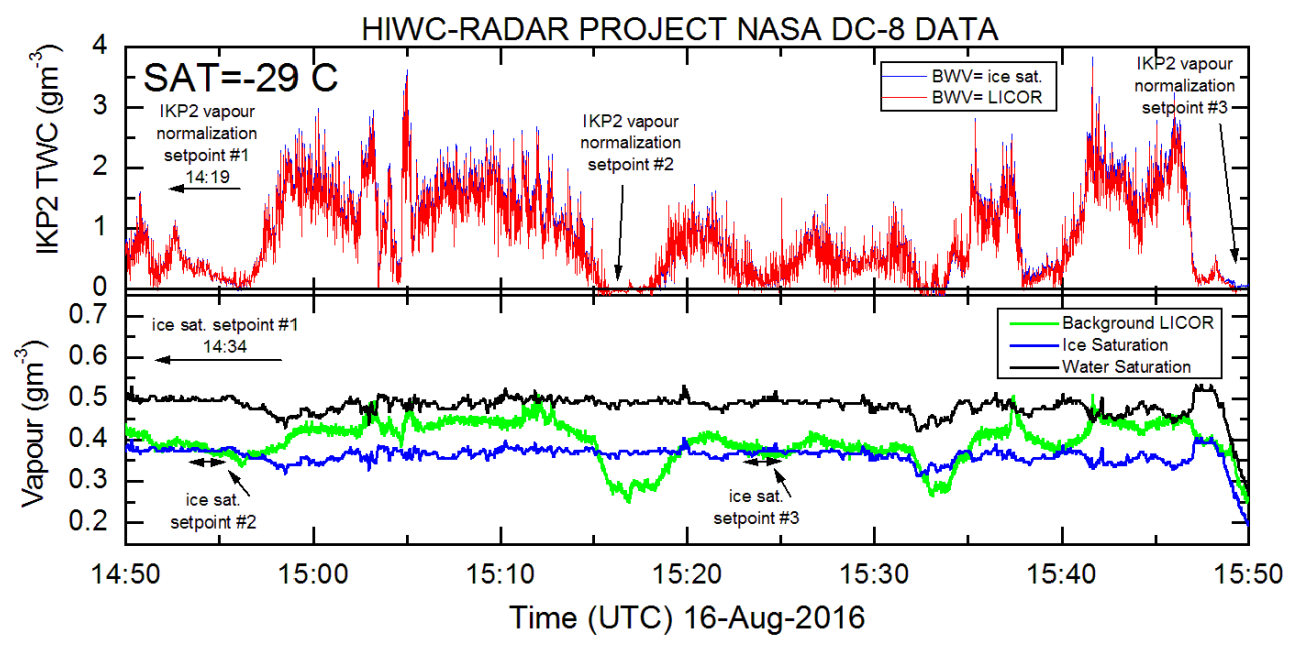

Figure 10.-Time series from a flight in high IWC, illustrating a water vapour normalization procedure to remove LICOR offsets, and the resulting estimates of in-cloud humidity. Setpoints for ice-saturation normalization of the background LICOR are shown in the lower figure, and for the IKP2 LICOR are shown in the upper figure. The comparison of IKP2 TWC estimates using simple ice saturation versus the actual measured LICOR in-cloud background readings is shown in the top figure.

force them to ice saturation values. This procedure is performed at appropriate intervals decided by the analyst, usually with sepoints chosen braketing major cloud events and times of altitude changes, and offsets are interpolated between the chosen set points. The IKP2 water vapour instrument is then normalized to the adjusted BWV measurement in a stable region outside of cloud. This procedure forces the IKP2 and BWV measurements to be equal out of cloud at the set points, and thus the out-of-cloud IKP2 TWC to be zero. Relative drift between the two instruments is then removed by additional out-ofcloud set points if required, and linear interpolation of offsets in between. Figure 10 shows an example from a flight in high IWC cloud at $-29^{\circ} \mathrm{C}$. The normalization of the BWV to ice saturation is performed at three set points in this cloud area, two of which are identified in the time series; all are areas of lowmoderate IWC cloud with no evidence of supercooled LWC. The IKP2 LICOR is then normalized to the adjusted BWV at two set points before entry and after exit of the cloud, and one during a brief exit of cloud in the center of the figure. Ice and water saturation values are computed from atmospheric state parameters, and are plotted on the lower panel along with the normalized BWV. In this case, the magnitude of the set point adjustments applied were less than $0.01 \mathrm{gm}^{-3}$ for the BWV LICOR, and -0.2 to $-0.3 \mathrm{gm}^{-3}$ for the IKP2 LICOR. Note that as expected the BWV values are close to ice saturation at the set points, but rise in cloud to approximately the water saturation values where the maximum values of IWC are observed. Are these rises real, or are they due to ice ingestion into the BWV air line or some other effect? They are clearly correlated to the amount of IWC, as might be expected if the rise were due to ice ingestion or submimation contamination. Presently, the answer to this question is not fully resolved. This BWV uncertainty leads to uncertainty in the IKP2 TWC, as shown by the comparison of the two TWC traces in the upper panel of Figure 10. The red TWC line in the top panel uses the LICOR BWV value (green line, lower panel), and the blue TWC line assumes BWV is at ice saturation (blue line, lower panel). The differences are relatively small, and are highest when the IWC is the highest.

The overall behavior of the Falcon-20 BWV during the flight program has been examined using the above method. For temperatures colder than $-30{ }^{\circ} \mathrm{C}$, the measured $\mathrm{BWV}$ in cloud rarely exceeded the water saturation value, although rises above ice saturation were often highly correlated to IWC as in Figure 10. However at $-10^{\circ} \mathrm{C}$, water saturation was often exceeded, implying a contamination of the BWV measurement. Using the option of BWV at the computed ice saturation value (blue line, Figure 10, lower panel), on the assumption that the BWV measurement in cloud cannot be trusted, TWC errors at the short distance scales in high IWC clouds are estimated to be typically less than the difference between the 
ice and water saturation concentrations, assuming that an appropriate ice-saturated region of cloud has been chosen to normalize the LICORs. The uncertainties would be approximately $0.22,0.11$, and $0.06 \mathrm{gm}^{-3}$ for $-10,-30$, and $-40{ }^{\circ} \mathrm{C}$ respectively, and would tend to overestimate TWC. For longer distance scales, the errors decrease, as it is increasingly unlikely the cloud is entirely at LWC saturation at that scale. The other option, of using the actual normalized BWV measurement (green line, Figure 10, lower panel) has the potential for lower uncertainty, but only if there is confidence that the BWV is uncontaminated. A final decision on the best in-cloud BWV removal method is pending, subject to completion of further data analysis of the Cayenne-2015 flight program data.

\section{Wetting of Air Lines}

During both flight programs and wind tunnel investigations, wetting of the BWV air lines was occasionally observed, sometimes from ingestion of rain water before takeoff, or in the wind tunnel from inadvertent temporary leaking of moist ambient air from outside the tunnel during equipment reconfigurations, followed by condensation on the cold soaked airlines. The results were the same: a very elevated BWV measurement that slowly decreased with time as the airline dried out, with the real BWV variations superimposed on the elevated contaminated signal. It was possible in most of such cases to normalize the IKP2 and BWV measurements using the procedure outlined above, although more frequent re-normalizations were typically required with interpolation of offsets in between.

\section{Inlet Location and Design}

The design of the BWV inlet has been found to have a significant effect on BWV and thus IKP2 TWC measurements. Work is ongoing, and only general conclusions will be discussed here. There appear to be at least two in-flight considerations: hydrometeor ingestion and hydrometeor evaporation/ sublimation due to adiabatic heating induced by flow disruptions near the inlet. If hydrometeors enter the inlet airline, they can travel to the warmer aircraft cabin areas, melt and deposit on the walls, cause a saturation response, or even travel into the $50{ }^{\circ} \mathrm{C}$ LICOR-840A measurement cell and evaporate, spuriously elevating the BWV measurements. During the first flight program in Darwin, there were two BWV inlets. One was a rear facing inlet normally used for a General Eastern dewpoint sensor. The inlet was mounted on the top fuselage approximately $3 \mathrm{~m}$ ahead of the leading edge of the Falcon-20 vertical tail, with the air intake approximately $2 \mathrm{~cm}$ above the aircraft skin. The second inlet, also from a commercially available humidity system, was mounted flush to the aircraft top fuselage with an air channel parallel to the flow, from which air was sampled from a $90^{\circ}$ side tap. Post-campaign analysis suggested that both inlets may have had spuriously high BWV measurements in cloud, the latter inlet being significantly worse than the former. Since no reliable in-cloud humidity was available, for this project, BWV measurements used in the IKP TWC calculation were assumed to be at ice saturation (there were very few observations of liquid or mixed-phase clouds), incurring a first-approximation uncertainty equal to the differences in ice and water saturation (e.g., Table 3), as illustrated in Figure 10. In the second campaign, both BWV measurements were made on the Falcon-20 from a new reverse flow 'G-II inlet' with an ice crystal deflector cone. The inlet was mounted on the bottom fuselage near the rear of the aircraft, in a region that may experience reduced ice concentrations due to shadowing and other particle sorting due to flow effects (Ref. 33), and thus less potential for BWV contamination. The in-cloud BWV results from this project are still being assessed (e.g., Fig. 10), and although they do appear to be significantly better than those of the first project, there is still evidence of inlet contamination in high IWC conditions.

During the last wind tunnel tests of Table 2, a variety of inlets were tested to assess their effects on BWV measurements. Different results were obtained from different inlets, as illustrated in Figure 9, some but not all of which may be due to gradients in IWC from one inlet location to the next. Preliminary results from these tests suggest that a deflector ahead of the air inlet may reduce or eliminate ice ingestion. Results also suggest that significant obstructions ahead of the inlet may create adiabatic air temperature rises that can lead to local sublimation of ice particles and spurious elevation of the BWV 
measurement. Using an extension of the air inlet tube well beyond the end of the deflector, as proposed by Envirnonment and Climate Change Canada, may mitigate this effect. While a number of configurations with deflectors and inlet tube extensions were tested, the best results were obtained from the simpler reverse flow inlets with the least upstream obstruction. While falling short of identifying an air inlet that guaranteed uncontaminated BWV measurements, it was concluded that the overall effect of ice ingestion or inlet-induced sublimation can be important, and compromises the IKP2 TWC measurements by elevating the BWV by an uncertain amount. The authors are aware of at least two open path BWV systems that do not use an inlet, e.g., Reference 34, and may provide superior in-cloud measurements if installed in proper locations on an aircraft. These systems tend to be more complex and expensive, are not currently commercially available, and would need to be verified in high IWC conditions for the present application.

\section{Synchronization of IKP2 and Background Humidity, and Damping}

Out of cloud humidity in the vicinity of deep tropical clouds can be highly variable due to strong cloud circulations and turbulent mixing. In general, out of cloud measurements made by the IKP2 LICOR and the BWV LICOR are very similar and coherent. Figure 11 illustrates such a case from a Falcon-20 flight in Darwin at approximately $+10^{\circ} \mathrm{C}$, where the two LICORS track nearly exactly. Figure 11(b) shows the measurements as recorded, expressed in $\mathrm{gm}^{-3}$ for this discussion. The background LICOR has been adjusted up by a small amount to account for a near-constant offset from the IKP2. The variations in both measurements match closely, but there appears to be a phase difference of about $1 \mathrm{sec}$ between the two measurements, mostly due to the time required for the air to travel through the air line to the BWV LICOR. Although the two traces look almost the same in Figure 11(b), subtraction of the background LICOR humidity from that of the IKP2 to derive the out-of-cloud TWC, which should be zero if both measurements track perfectly, reveals large departures from zero of about $\pm 1 \mathrm{gm}^{-3}$ (Fig. 11(a)). By phase shifting the BWV LICOR by $1 \mathrm{sec}$ (Fig. 11(d)), the two signals appear to be now almost identical, and the calculated TWC (Fig. 11(c)) now shows a noise level of about $\pm 0.1 \mathrm{gm}^{-3}$. This example illustrates the sensitivity of the out-of-cloud IKP TWC measurement to BWV time synchronization. It also illustrates the excellent precision of the LICOR-840A in this example. This case shows a better than average out-ofcloud comparison for such a warm temperature. In practice, as background humidity increases with increasing temperature, and imperfections in the two measurements amplify, the out-of-cloud noise level rises. For the tropical environment we have found a practical upper limit of about $0{ }^{\circ} \mathrm{C}$ for IKP2 measurements, above which noise levels rapidly rise above $\pm 0.3 \mathrm{gm}^{-3}$. In other applications, such as in more stable atmospheres, or in wind tunnel operations, humidity variations are smaller, and the noise level of the IKP2 TWC may be quite acceptable at temperatures warmer than $0{ }^{\circ} \mathrm{C}$.

A damped BWV signal, perhaps as a result of using a BWV with a slower time response, or because of inadvertent air reservoirs in the BWV air sampling system, also deteriorates the out-of-cloud noise level on the IKP2 TWC. In Figure 12, the IKP2 signal itself is used both as the TWC and BWV measurement, but is artificially damped for BWV by back-averaging $2 \mathrm{sec}$ of data for illustration. The undamped data would obviously produce exactly zero out-of-cloud IKP2 TWC by definition. The nonzero IKP2 TWC in Figure 12(a) is the effect of the damping, in this case varying by about $\pm 0.5 \mathrm{gm}^{-3}$. In both Figures 11 and 12, the out-of-cloud baseline noise is clearly larger in regions of higher BWV fluctuations. In the quiet period between 26:21:20 and 26:21:38, the out-of-cloud TWCs are well behaved and near zero.

The above discussion has pointed out the importance of the BWV measurements in IKP2 TWC measurements in tropical clouds, where out-of-cloud humidity gradients are large, possibly affecting IKP2 out-of-cloud noise levels due to an imperfectly synchronized and/or a damped BWV signal. When TWC values are very large, possible inlet-induced contamination effects may become important, leading to uncertainty as to what to use for in-cloud BWV to support IKP2 TWC calculations. Although BWV is negligible at the coldest flight temperatures, increasing care must be taken at warmer flight temperatures due to the increase in the magnitude of the BWV signal. 

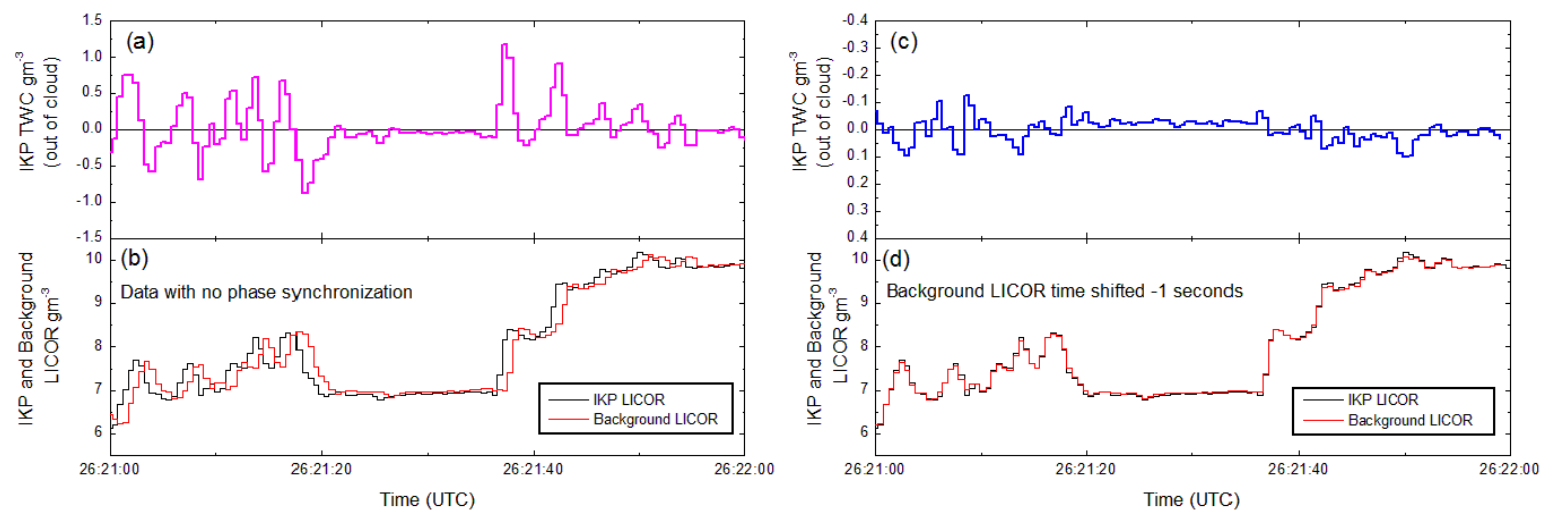

Figure 11.-Example of Falcon-20 out-of-cloud water vapour measurements with the IKP2 and the background LICOR-840s in a particularly variable atmospheric humidity field during the HAIC-HIWC Darwin flight program. Figure 11(a) shows the measurements as received, and Figure 11(b) shows the resulting IKP2 TWC, which should be zero if the two measurements tracked perfectly. Figure 11(d) shows the same measurements as Figure 11(b), but with the background LICOR phase shifted by -1 sec. Figure 11(c) shows the resulting improved IKP TWC using the phase-shifted data (note the scale difference).

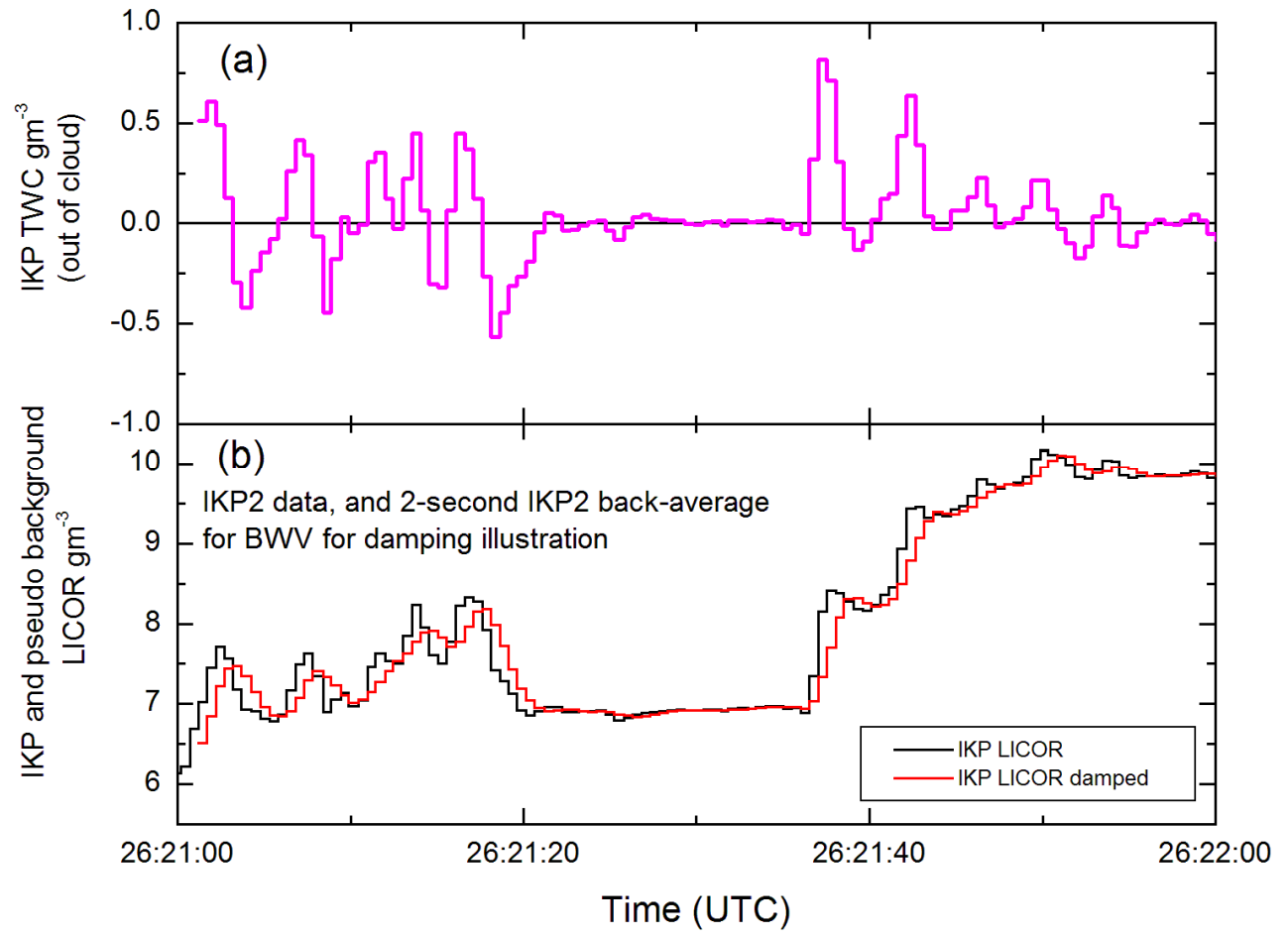

Figure 12.-As in Figure 11, but (a) 2-sec back-average of IKP2 LICOR signal has been used as BWV to illustrate effect of damping of BWV measurement. Resulting out-of-cloud IKP2 TWC calculation is shown in (b). 


\section{Estimation of Accuracy Through Testing and Comparison to Other Instruments}

\section{A. Field Calibration Cart}

A field calibration cart (FCC) was developed by Science Engineering Associates to make periodic high LWC checks during flight projects to verify continued proper operation of the evaporator and other components. The FCC also provides an important estimate of the absolute accuracy of the instrument. A vacuum pump is used to suck air through the IKP2 flow system at an adjustable rate. The IKP2 measures the mass flow of the air through the flow path, and sets the flow valve to provide the desired true airspeed at the inlet. There is an independent mass flow cross-check. A solenoid triggered syringe supplies a metered rate of liquid drops in a stream directly into the inlet. For best results, the relationship between the mass flow through the syringe versus solenoid trigger rate is checked during each calibration by capturing and weighing the injected water for a measured time. BWV is measured by the IKP2 itself for subtraction during periods with no liquid injection. The FCC is typically operated to provide a series of known user-selectable LWC steps from about $1 \mathrm{gm}^{-3}$ to in excess of $40 \mathrm{gm}^{-3}$, all within the LICOR-840A upper measurement limit of $60,000 \mathrm{ppm}$. Figure 13 illustrates an example of a recent FCC laboratory calibration of IKP2-2. The IKP2-2 LWC measurement agrees very well with the FCC estimate over this very wide range of LWC inputs. The best fit through the origin has a slope of 0.987 . The average IKP2-2 minus FCC percent difference for all points (not shown) is -0.70 percent. Similar agreements have been found in other calibrations with IKP2-2 and IKP2-1. Slopes of IKP2-1 versus FCC LWC regressions through the origin over seven calibrations between 24 Feb. 2014 and 17 Dec. 2015, two being in more difficult outdoors settings with the IKP2-1 installed on the aircraft, vary between about 0.974 and 1.037, with a mean value of 1.000 . There was no noticeable trend in these ratios with time, a testament to the stability of the IKP2 and the FCC. For the IKP2-2, the corresponding slopes for six calibrations between $10 \mathrm{Feb} .2015$ and $26 \mathrm{Feb} .2016$ vary between 0.959 and 1.015 , with a mean value of 0.9910 . The average IKP2 minus FCC percent difference for all IKP2-1 and IKP2-2 comparisons were 0.22 and 0.76 percent, respectively.

The results of the FCC calibrations are important. Based on the slopes of the regression lines, they collectively indicate an agreement to the calibration reference for both probes within about \pm 4 percent. The FCC checks the probe accuracy in ambient conditions in an end-to-end fashion. Accuracy factors included in this check are (1) a large fraction of the software calculations of the IKP2, (2) the mass flow

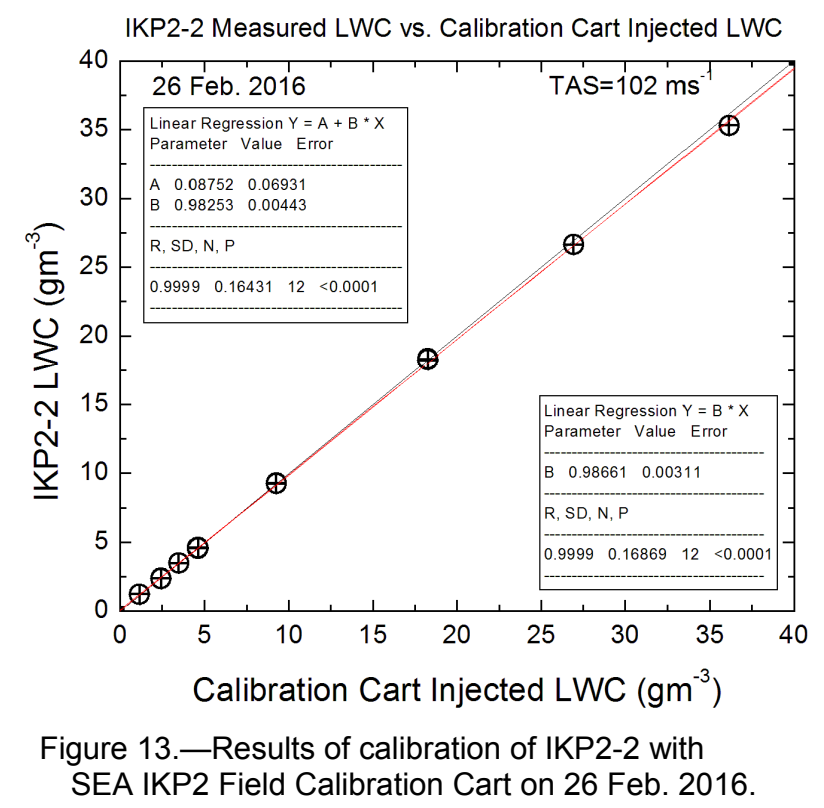


meter estimates, and (3) the LICOR-840a accuracy. For example, the desired inlet airspeed for a calibration is set by inputting the value into the IKP2 real-time software, along with the ambient pressure and temperature. The IKP2 then adjusts the valve setting to throttle the flow back to a mass flow equivalent. If the IKP2 calculates too low a value of the desired mass flow, or sets the valve to provide too low a mass flow, or measures too low a flow with the orifice plate, the injected water would be evaporated in less air volume, and the computed IKP2 LWC would be higher than that calculated based on injected water rate and the intended true airspeed. Similarly, a scale factor error in the LICOR-840A measurement would result in an equivalent scale factor error in the IKP2 versus calibrator TWC comparison. In fact, the only accuracy factor that is not checked in this end-to-end LWC calibration is the effective inlet diameter defining the sweep-out of hydrometeors, since the water is injected in a stream in the center of the inlet.

\section{B. Comparisons to Tunnel Reference Values in LWC Conditions at the NASA Icing Research Tunnel}

The NASA Icing Research Tunnel is a well-documented facility for icing research in LWC conditions. The tunnel has been carefully calibrated for LWC and MVD, and spray conditions can be produced with a high degree of repeatability. LWC calibrations in the facility were historically performed using an icing blade, but have been changed in recent years (Ref. 35). The calibration procedure now uses the TWC sensor of the SEA multi-element hot-wire probe, which is believed to have a more accurate estimate of LWC at high MVD values, and has been shown to agree well with the icing blade estimates for MVD values less than $50 \mu \mathrm{m}$. The overall accuracy of the IRT LWC values is estimated to be about \pm 10 percent, percent which includes variations from measured data and curve fits. The repeatability of LWC has a standard deviation of approximately 2.6 percent (Refs. 35 to 36, and Robert Ide, personal communication).

A series of test points were carefully chosen with the help of IRT staff to optimize the accuracy of the comparison. Most were actual points used to calibrate the tunnel. This minimized any small discrepancies due to interpolation in the general IRT calibration. The IKP2 probe was installed in the middle of the tunnel, where tunnel calibrations are performed, and a SEA multi-element probe was installed $39.1 \mathrm{~cm}$ off center as a general reference to help identify any abnormalities in the tunnel conditions and as an offcenter reference to the tunnel calibration. Special runs were performed with the IKP2 alone in the tunnel, and then with the SEA multi-element at its side, to demonstrate that the IKP2 measurement was minimally affected by the multi-element probe. A series of LWC set points at approximately $20 \mu \mathrm{m}$ MVD and $77 \mathrm{~ms}^{-1}$ (calibration values 1.04 to $\left.3.03 \mathrm{gm}^{-3}\right), 102 \mathrm{~ms}^{-1}\left(0.87,1.81 \mathrm{gm}^{-3}\right)$, and $128 \mathrm{~ms}^{-1}(0.62$, $1.93 \mathrm{gm}^{-3}$ ), and MVD set points at approximately 0.5 to $0.6 \mathrm{gm}^{-3}$ spanning 15 to $196 \mu \mathrm{m}$ MVD were tested. The two copies of the probe, IKP2-1 and IKP2-2, were tested one day apart. A total of 18 IKP2-1 and 21 IKP2-2 runs are included in the following comparisons, composed of 14 unique conditions and repeats. Total air temperature values were kept constant at approximately $-10{ }^{\circ} \mathrm{C}$.

An example of a sequence of three LWC settings is shown in Figure 14(a). As in almost all tests, the duration of individual settings was $3 \mathrm{~min}$. After the spray was turned off, the systems were observed until stabilization, and the next LWC setting was requested typically 3 to $5 \mathrm{~min}$ after the end of the previous setting. Averages of the IKP2 TWC were calculated for a 2-min period chosen by inspection commencing after stabilization of the spray. BWV values were measured in three different locations: on the tunnel wall out of the main LWC cloud using a reverse flow G-II inlet as described earlier, on the side of the IKP2 in the cloud using second G-II inlet, and behind the vertical strut of the IKP2 using a reverse flow tube with a deflecting cone, the tube not extending out of the cone. Corresponding measurements from these inlets for the sequence of Figure 14(a) are shown in Figure 14(b). As common to all test runs, the various LICOR-840As were found to have offsets in out-of-cloud conditions, and a normalization procedure was used such as that described in Figure 9 to remove the offsets. In this case, all of the LICORs were normalized to water saturation values for a stable 15 -sec period just prior to each spray, even though it was likely that conditions were sub saturated. The logic here was that the normalization procedure does 


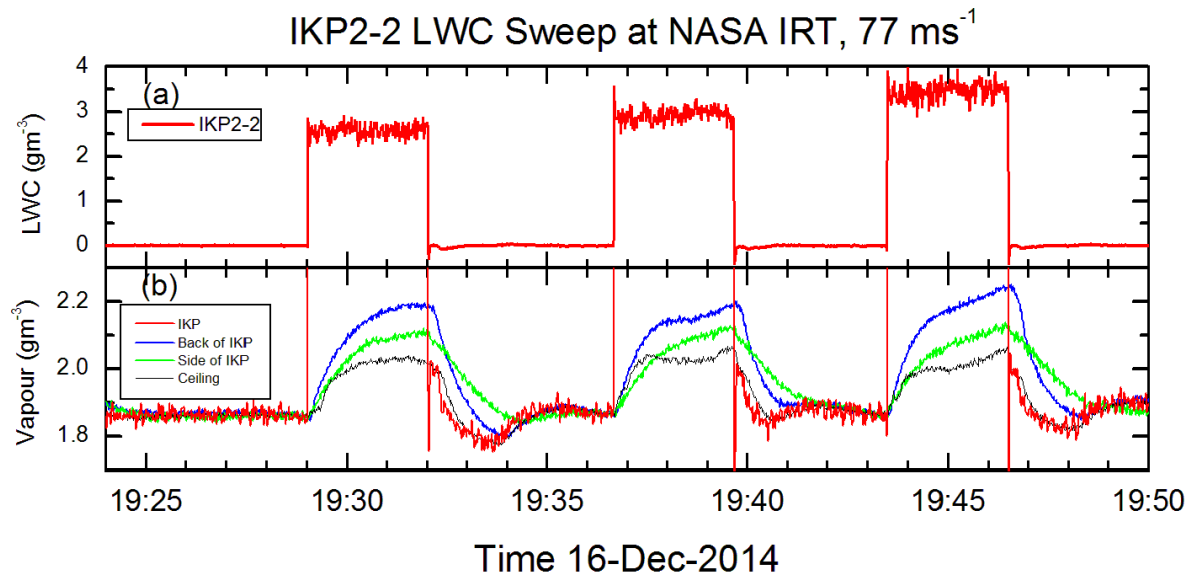

Figure 14.-Example sequence of 3 LWC settings during testing at the NASA IRT (test 6, Table 2). Bottom panel (b) shows IKP2-2 total vapour measurement, and background water vapour measurements from three inlets, and top panel (a) shows IKP2-2 LWC calculated using ceiling-mounted inlet water vapour.

not require an absolute reference for IKP2 TWC calculation, just a common one. This procedure, in addition to removing bias between the IKP2 and BWV LICORs, would also bring all the humidity values closer to accurate absolute values. During the testing, the side and aft inlets were found to collect ice on the inside of the inlet deflecting cones, and it was concluded that LWC may therefore have entered the inlet airline and contaminated BWV. No such ice was observed on the ceiling inlet, probably because it was outside the main cloud. Furthermore, when examining the response of the BWV measurements just after the sprays were turned off (e.g., 19:32:00, Fig. 14(b)), the ceiling mounted vapour measurement (black line) closely followed the IKP2 vapour measurement (red line), while the side (green) and aft (blue) inlet measurements lagged behind, and were in excess of the IKP2 measurement by up to $0.2 \mathrm{gm}^{-3}$. The side and aft inlet responses are consistent with a contaminated BWV signal, and the ceiling BWV signal agrees well with the IKP2 before and immediately after the cloud. Consequently, the ceiling BWV measurements were used in the IKP2 subtraction to obtain IKP2 LWC. Note also that there was still a small lag in the ceiling BWV that was not removed, perhaps due to the time required for the air to reach the LICOR through the airlines. This led to an offset in the out-of-cloud IKP2 baseline dropping to about $-0.08 \mathrm{gm}^{-3}$ and then rising to about $0.04 \mathrm{gm}^{-3}$ (not shown) before stabilization. The high frequency noise on the IKP2 baseline was about $\pm 0.01 \mathrm{gm}^{-3}$. The relatively low noise level here illustrates that the effects of poor synchronization and damping of BWV measurements may be less important in wind tunnel versus aircraft measurements due to the relative homogeneity of the wind tunnel BWV relative to the potentially highly variable out-of-cloud humidity fields in the latter, especially near deep tropical convection.

Figure 15 contains the comparison of the IKP2-1 and IKP2-2 LWCs to the tunnel calibration for all 39 test points noted above. A small correction has been applied to the IRT calibration points to adjust them to the actual airspeeds measured on each run. The best fits of the data pass close to the origin for both probes. There appears to be a scale factor difference between each IKP2 and the tunnel calibration values: IKP2-1 and IKP2-2 measure about 10 and 12 percent higher respectively than the tunnel calibration values. Given that the estimate for the IRT tunnel calibration is 10 percent, the calculated system accuracy of the IKP2 is about 2 to 3 percent for TWC excluding BWV considerations (Ref. 10), and allowing for a small remaining uncertainty in the BWV measurement, it is reasonable to conclude that although the scale factor difference is highly defined, the differences between the measurements are within the uncertainty of each measurement. 


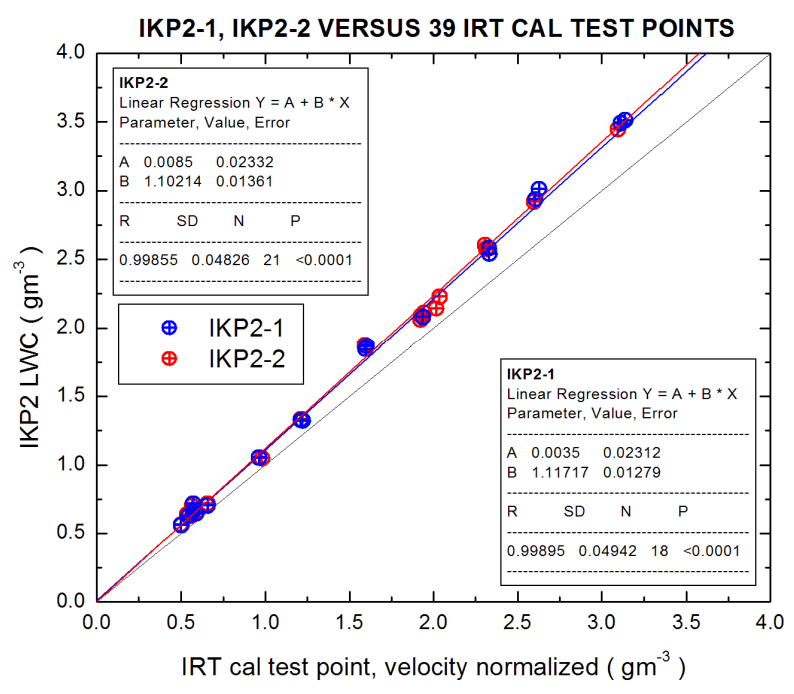

Figure 15.-Comparisons of the LWC measured by the IKP2-1 and IKP2-2 probes to calibration points at the NASA lcing Research Tunnel (test 6, Table 2). IKP2-1 (blue points) and IKP2-2 (red points) measurements were made in separate tests one day apart. Settings spanned 77-128 $\mathrm{ms}^{-1}$ true airspeed, and 15-196 $\mu \mathrm{m}$ MVD.

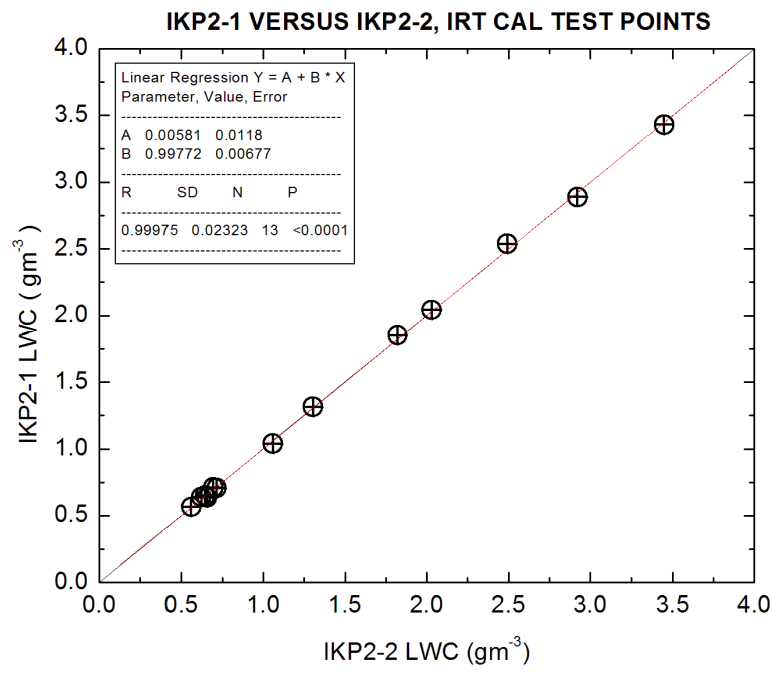

Figure 16.-Comparisons of the LWC measured by the IKP2-1 and IKP2-2 probes for 13 common test conditions one day apart (test 6 , Table 2). Settings spanned $77-128 \mathrm{~ms}^{-1}$ true airspeed, and 15 to $196 \mu \mathrm{m}$ MVD.

The precision of the IKP2 is very high. Figure 16 plots 13 common calibration points with repeats measured by IKP2-1 and IKP2-2 one day apart, each at the center of the tunnel. The data have been normalized for small variations from the target airspeed. The data from the two probes is nearly identical. The offset in the regression is very small, and the slope of the regression line is 0.998 . The standard deviation of the LWC differences between the two probes is 0.91 percent. This high degree of precision is also a testament to the high degree of repeatability of the tunnel LWC, since these differences also include any contribution from imperfect tunnel repeatability. 


\section{Exploratory Comparisons to an Independent Bulk IWC Measurement at the NRC M7 Test Cell 5 Wind Tunnel}

As has been discussed earlier, the IKP1 and IKP2 probes were developed after it was concluded by the EHWG that there was no probe available with a defensible TWC accuracy estimate of 20 percent or better in high IWC conditions. The assessment of the IKP2 IWC measurements is not as straightforward as for LWC. Facilities for wind tunnel simulation of ice clouds are less developed and more difficult to calibrate. IWC calibrations currently use exploratory methods that have not been rigorously validated. Control over parameters such as the median mass diameter (MMD) of the ice particles is limited.

For the assessment of the IKP2 IWC accuracy, the IKP2 development team explored methods at the NRC M7 test cell 5 (M7TC5) open tunnel. This tunnel has no ice particle recirculation and thus it has the potential to estimate IWC knowing the amount of ice injected into the tunnel and its spatial distribution. work in calibrating the IWC in this tunnel used such a mass-balance technique (Ref. 16). The disadvantage of the technique is that determining the spatial distribution requires laborious IWC tunnel mapping of that cannot practically be done on a routine basis, and it is unknown whether spatial distribution remains adequately constant over time to apply the method over long periods. In 2010, the IKP2 development team became aware of the ice capture cylinder (ICC) method, which was first used in ice cloud simulations in Europe, and a comparison of the two methods was performed in 2011, before the IKP2 was completed. In the process of these comparisons, the first of a number of peculiarities of the ICC technique was identified. In particular, at the operational airspeed of about $150 \mathrm{~ms}^{-1}$, the length of the cylinder was found to affect the amount of ice captured: $10 \mathrm{~cm}$ cylinders captured less than $20 \mathrm{~cm}$ cylinders with a gradual $90^{\circ}$ bend, which in turn captured less than straight $20 \mathrm{~cm}$ cylinders. A single measurement with a $30 \mathrm{~cm}$ ICC revealed no further increase in capture with length. In 2011, measurements from the 20-cm ICCs were compared to the mass-balance IWC estimates and found to agree within 10 percent, a surprisingly good result, but concern about the stability of 2009 mapped spatial distribution led us to conclude that in-situ ICC measurement at the location of the instrument was the best approach going forward.

Comparative IKP2 and ICC IWC measurements were finally made at M7TC5 in Jan. 2016 (test 7, Table 2). Exploratory measurements with the ICCs in earlier testing at about $80 \mathrm{~ms}^{-1}$ (test 5, Table 2) had provided visible evidence of occasional loss of mass from the ICC during extraction, and that data fidelity could be improved by comparing duplicate measurements from two ICCs side by side. Although some differences were expected because of spatial gradients, the ratios of the masses were found to be approximately constant for a large fraction of measurements, and significantly different for others that were concluded to suffer this extraction mass loss, or some other mass loss effect. This technique of double measurements was used during the Jan. 2016 testing as a quality control to minimize the effect of such events. In addition, transparent polycarbonate cylinders were exposed during special capture experiments to help understand the collection process. These experiments were very revealing, and helped explain why collections with $10 \mathrm{~cm}$ cylinders provided lower collections at $150 \mathrm{~ms}^{-1}$ than $20 \mathrm{~cm}$ cylinders. The ice plug formed near the mouth of the $10 \mathrm{~cm}$ cylinder, and thus the leading edge of the plug was susceptible to loss of captured ice by re-entrainment. For $20 \mathrm{~cm}$ cylinders, the ice was found to initially form at the back of the cylinder, with the leading edge of the ice plug moving forward with time. In some cases, the ice plug separated into two pieces. Some ice was observed to deposit on the walls up to near the mouth of the cylinder, appearing to move slowly forward along the wall. An area of swirling ice could sometimes be seen at the leading edge of the ice plug. An example image after an ice collection is given in Figure 17, and it will be further discussed below.

The IKP2-1 was mounted with its inlet in the center of the circular M7TC5 tunnel sample section. Other measurements in the tunnel during the ICC runs included BWV from 3 different inlets, and a SEA Robust hot-wire probe mounted about $23 \mathrm{~cm}$ above the center of tunnel. Ice particles with an MMD of approximately $200 \mu \mathrm{m}$ were generated by an ice shaver, and injected into the tunnel at 4 points near the mouth of the open tunnel, as described elsewhere (Refs. 16 and 23). Dual 20-cm stainless steel ICCs were inserted into the tunnel after the IKP2-1 IWC time series had stabilized, and were usually extracted at the 
time the ice shaver was turned off. One cylinder was exposed directly in front of the IKP2-1 inlet in the tunnel center. The other cylinder was about $2.4 \mathrm{~cm}$ off the horizontal center. Figure 18 shows a picture of the ICC mast inserted in front of the IKP2-1, although with a 10/20 cm combination that was not used for IKP2-1/ICC comparisons rather than the regular 20/20 cm cylinder combination.

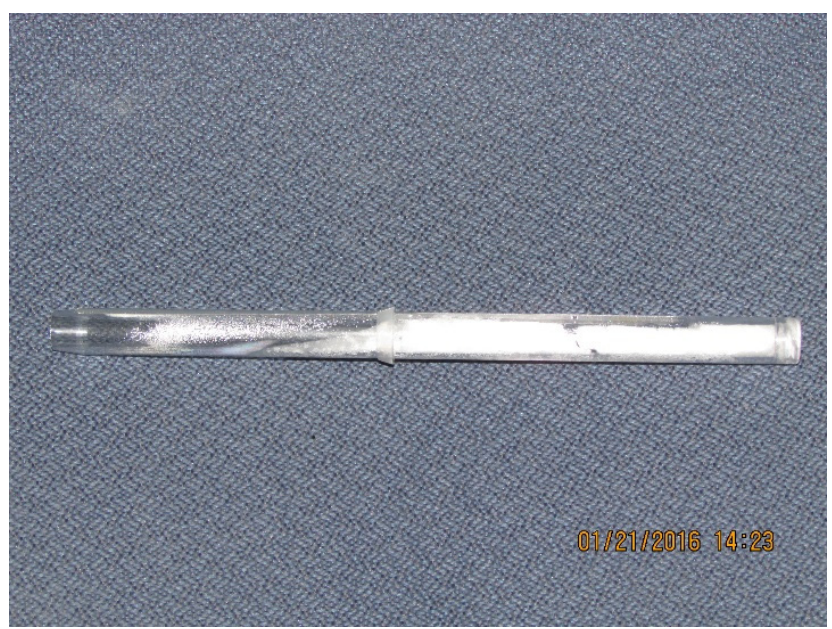

Figure 17.-Ice bulk capture using $20 \mathrm{~cm}$ transparent polycarbonate cylinder at $150 \mathrm{~ms}^{-1}$, (test 7 , Table 2). The accumulated from the back of the cylinder (right), but the plug was visible at the end of the capture as two pieces. Note the thin accumulation of ice at the left on the forward wall near the cylinder mouth.

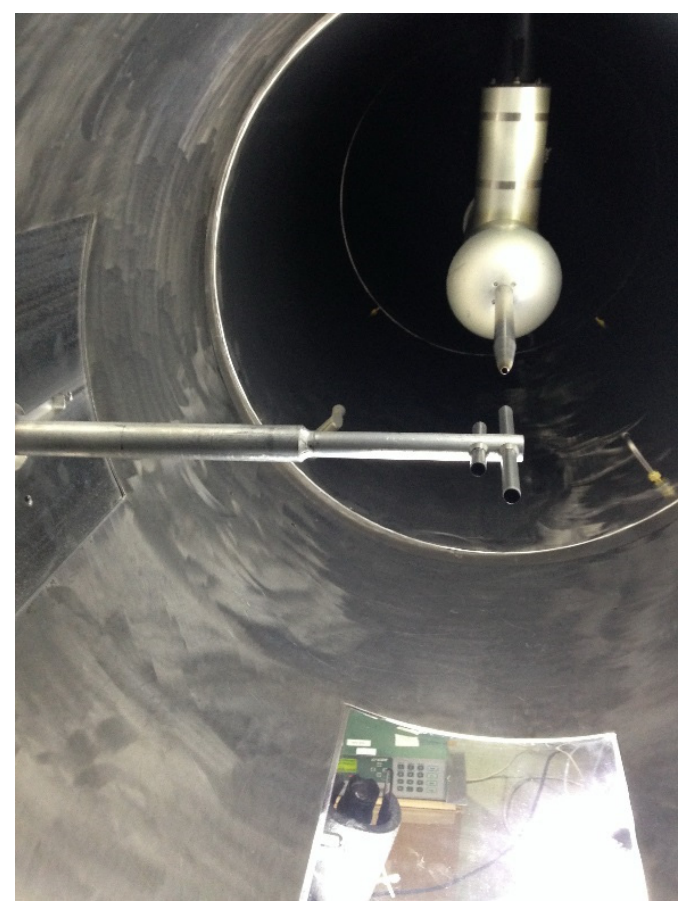

Figure 18.-Photo showing ICC mast inserted into the tunnel in front of the IKP2-1 (test 7, Table 2). In this case, a $20 \mathrm{~cm}$ cylinder is in front of the IKP2 inlet, and a $10 \mathrm{~cm}$ cylinder is beside. All IKP2-1/ICC comparisons use $20 \mathrm{~cm}$ pairs. Also shown at bottom is transparent window and video camera used to visualize experiments with polycarbonate cylinders. 
A total of 6 ice shaver rates, producing IKP2-1 IWCs spanning from about 0.7 to $4.4 \mathrm{gm}^{-3}$, were used for the comparisons. At most shaver settings, there was insufficient time to get an adequate sample of both the IKP2-1 measurement and the ICC bulk collection on the same run, due to the finite length of the ice block being shaved. Consequently, the typical procedure was to perform an entire pre-ICC run for the IKP2-1 measurement without the ICC exposed, followed by an ICC exposure run, and finally a post-ICC IKP2-1 run again with no ICC exposure. The pre and post IKP2-1 time series were averaged over an equivalent stable time period, averaged together, and then compared to the IWC calculated from the bracketed ICC exposure run.

The ICC IWC was computed using the following formula:

$$
\mathrm{ICCIWC}=\frac{m_{c}}{\varepsilon A V \Delta t}
$$

Where $\mathrm{m}_{\mathrm{c}}$ is the mass of the collected ice, $A$ is the area of the inlet, $V$ is the tunnel velocity, $\Delta t$ is the exposure time of the ICC, and $\varepsilon$ is the collection efficiency. Most of these are relatively well know. The diameter of the collection cylinder was measured with a micrometer across 4 diameters and averaged. The velocity was measured by tunnel systems and estimated to be within $1 \mathrm{~ms}^{-1}$, and since it was used in both the ICC and IKP2 IWC measurements, velocity errors introduce no net uncertainty in the relative comparisons. The exposure time is probably accurate to within about $2 \mathrm{sec}$, leading to an increasing uncertainty as ICC IWC increases, from approximately 0.5 percent at $0.7 \mathrm{gm}^{-3}$ to about 3.5 percent at $4.4 \mathrm{gm}^{-3}$. The mass of the collection is calculated by subtracting the exposed cylinder mass to its dry empty mass. The scale was checked with calibration weights, and found to be accurate to within $0.01 \mathrm{~g}$. Since the collections varied between about 1 and $4 \mathrm{~g}$, the uncertainty in the $\mathrm{m}_{\mathrm{c}}$ values varied from about 0.25 to 1 percent. Regarding the value of $\varepsilon$, since the MMD of the ice particles is about $200 \mu \mathrm{m}$, the particles can be considered ballistic with unity collection efficiency. However, as will be discussed below, there are likely other factors reducing the efficiency of the final mass collection. For the purposes of ICC IWC calculation, the value of $\varepsilon$ is chosen to be unity.

To account for biases in the IWC values due to small differences in airspeed and measured shaver rate from run to run, both the IKP2-1 and ICC IWC values have been normalized to an airspeed of $150 \mathrm{~ms}^{-1}$ and the nominal shaver rate as per the following:

$$
\mathrm{IWC}_{N}=\frac{\mathrm{IWC}_{m} \mathrm{VS}_{\text {ref }}}{V_{\text {ref }} S_{m}}
$$

where $\mathrm{IWC}_{N}$ is the velocity and shaver rate -normalized IWC, IWC $m$ is the measured IWC, $V_{\text {ref }}$ is the $150 \mathrm{~ms}^{-1}$ reference velocity, $S_{m}$ is the measured shaver rate, and $S_{r e f}$ is the nominal reference shaver rate for the setting. Taking into account the uncertainties noted above, it is reasonable to conclude that the ICC $\mathrm{IWC}_{N}$ calculations should have an uncertainty of $<5$ percent, excluding the consideration of the efficiency uncertainty.

Regarding the IKP2 TWC calculation, there is some small but not insignificant uncertainty due to the BWV measurement, which is subtracted from the IKP2 total measurement to obtain IWC. During the last three days of testing, a number of different inlets were compared to evaluate their effects on BWV. An example of these comparisons is included in Figure 9, where a span of about $0.15 \mathrm{gm}^{-3}$ was observed from the highest to the lowest in-cloud BWV measurement (highest is LBCK2, rear-facing inlet aft of IKP2 strut; lowest is LBCK3, an experimental NASA rear-facing inlet in front of the IKP2, with a cone deflector, and a $4.4 \mathrm{~cm}$ tube extension past the deflector). During the actual ICC runs, which were performed before the inlet testing, only one inlet was always available, the wall-mounted G-II inlet described earlier, and hereafter referred to as the reference G-II inlet. For consistency only its data has been used for BWV subtraction in the IKP2 TWC calculations. Unfortunately, it now appears that other 
inlets, if they had been available, would have been better choices. Estimated errors resulting from the use of this reference inlet will be described below.

The BWV measurements of Figure 9 showed an unexpected in-cloud reduction for two inlets. The reference G-II inlet showed a slight increase in cloud. A reduction in BWV can only be explained by a transfer of vapour from the air to the ice crystals, only occurring if the air is supersaturated with respect to ice. It is believed that this unexpected situation resulted from the approximately $11^{\circ} \mathrm{C}$ static temperature decrease from the mouth of the tunnel to the sample section at $150 \mathrm{~ms}^{-1}$. In special tests at $80 \mathrm{~ms}^{-1}$, with only a $4{ }^{\circ} \mathrm{C}$ temperature decrease, the in-cloud reduction in the BWV was not observed, presumably because the air temperature was not lowered sufficiently to induce supersaturation. The results indicate that the BWV increases in cloud at $150 \mathrm{~ms}^{-1}$ measured by the other two inlets are false, perhaps due to ingestion of ice crystals or sublimation of ice in local areas of adiabatic temperature rise in partially stagnated flow around obstructions. During testing over the three final days with even more inlet configurations, an in-cloud decrease in BWV was a consistent observation at $150 \mathrm{~ms}^{-1}$ for all inlets with deflectors and a minimum up-flow obstruction. The decrease relative to the reference G-II inlet varied from about 0.03 to $0.1 \mathrm{gm}^{-3}$, was not particularly sensitive to IWC, and was most often between 0.05 and $0.07 \mathrm{gm}^{-3}$. It cannot be categorically concluded that reference G-II inlet over-read the BWV during all of the remaining 30 ICC measurements, but the available evidence suggests that it did so by about 0.03 to $0.10 \mathrm{gm}^{-3}$. Consequently, all 34 reference G-II BWV measurements have been decreased by an intermediate value of $0.065 \mathrm{gm}^{-3}$ in the IKP2 TWC calculation. The uncertainty in this correction is of the order of $\pm 0.04 \mathrm{gm}^{-3}$. It should be noted that this correction will have the tendency to slightly worsen the agreement of the IKP2 and ICC measurements.

Comparisons of the 34 ICC and IKP2-1 IWC values are given in Figure 19. The IKP2-1 IWC values are consistently higher than the ICC IWC. The slope of the best fit line through the origin is about 1.15. The overall average ratio of IKP2/ICC IWC for all the points in Figure 19 is 1.20 . The ratio of the IKP2/ICC actually decreases with increasing IWC, from 1.33 at a nominal $0.7 \mathrm{gm}^{-3}$ to 1.15 at a nominal $4.4 \mathrm{gm}^{-3}$, minimizing at about 1.09 at a nominal $2.6 \mathrm{gm}^{-3}$. There appears to be some factor either decreasing the ICC or increasing the IKP2 estimate relative to the other at low IWCs. Another way to illustrate the data is to plot the results as a function of the ice delivery rate. If the spatial distribution of the ice in the tunnel does not vary with the amount of ice delivered, the IWC measured at the center of the tunnel should be linear with respect to ice delivery rate, and the linear fit line should pass through the

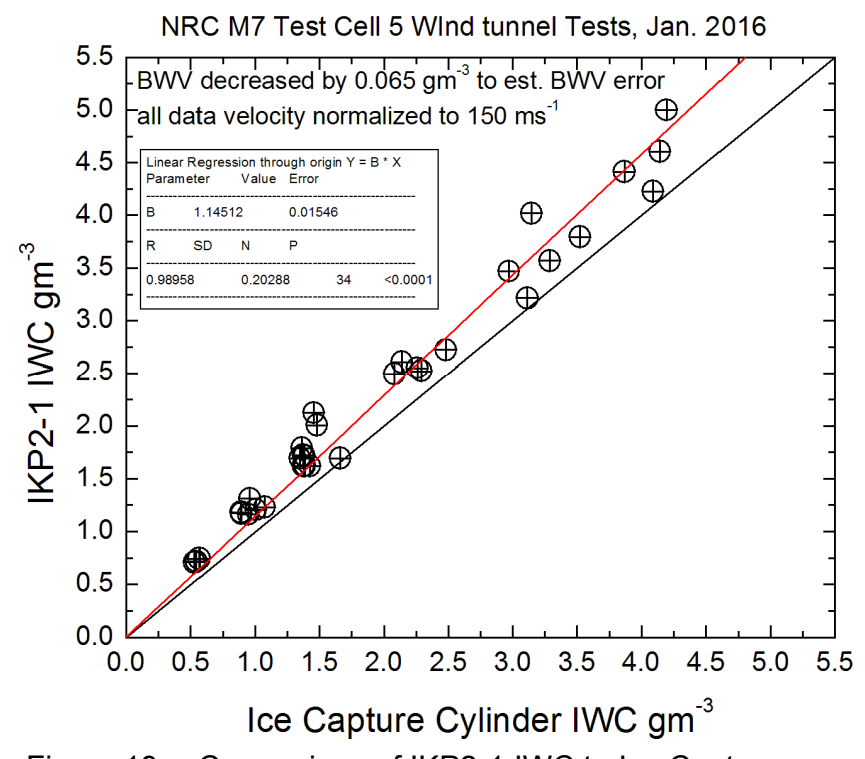

Figure 19.-Comparison of IKP2-1 IWC to Ice Capture Cylinder bulk estimates at the NRC M7 Test Cell 5 wind tunnel in January 2016 (test 7, Table 2). 
NRC M7 Test Cell 5 Wind Tunnel Tests, Jan. 2016
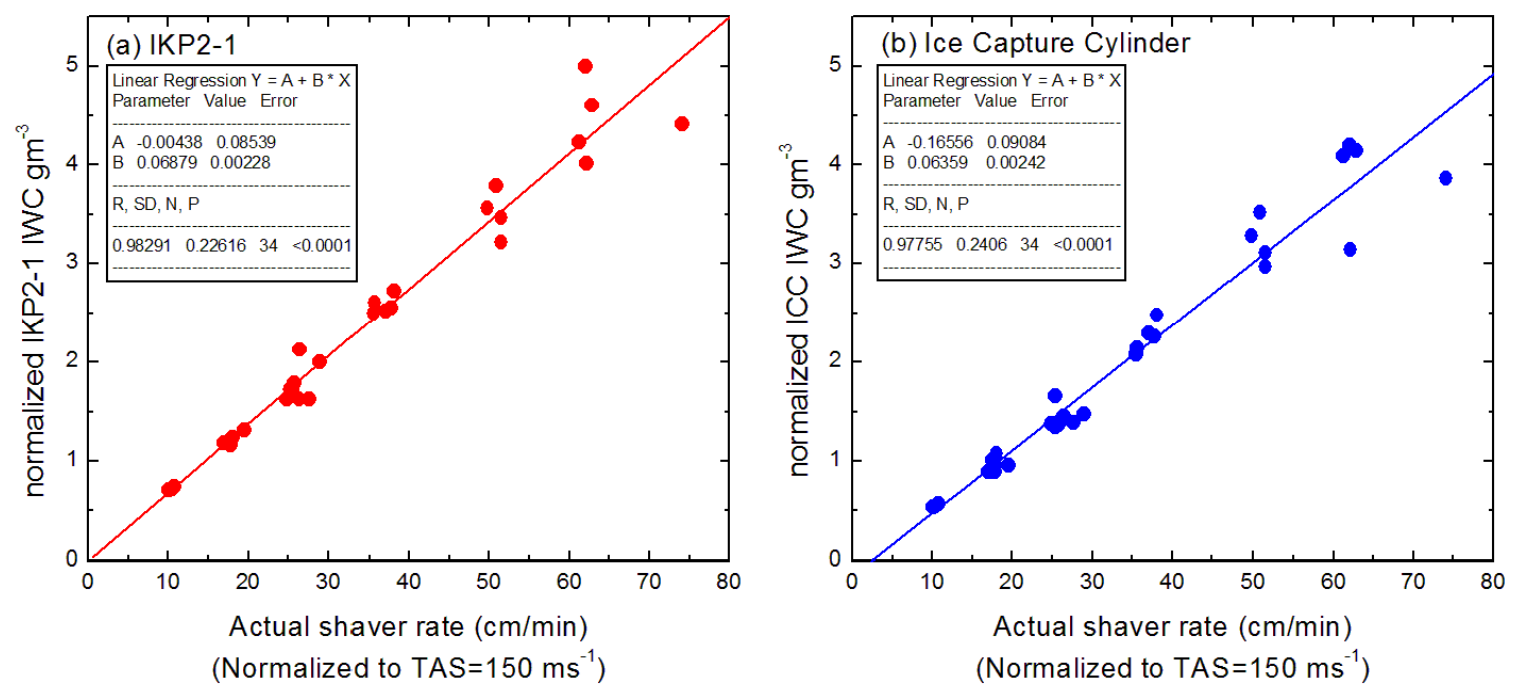

Figure 20.-Measured (a) IKP2-1 IWC and (b) Ice Capture Cylinder bulk IWC estimates as a function of normalized ice delivery rate at the NRC M7 Test Cell 5 wind tunnel in January 2016 (test 7, Table 2).

origin. Figures 20(a), (b) show the IKP2-1 and ICC IWC estimates as a function of ice delivery rate for the 34 ice capture comparisons. Note that the IKP2-1 best fit line fits the data well, and passes within $-0.004 \mathrm{gm}^{-3}$ of the origin (Fig. 20(a)). The corresponding best fit line for the ICC points has an intercept of about $-0.17 \mathrm{gm}^{-3}$. Considering that the IKP2-1 shows no tendency to overestimate LWC at low values during the NASA IRT tests (test 6, Table 2), we believe that the results of Figure 20(a), (b) indicate an increasing ICC underestimate rather than an IKP2-1 overestimate as IWC decreases.

The ICC method as tested appears to be subject to a number of factors all leading to IWC underestimate. The ICC is subject to a certain degree of random loss of captured ice when extracting the cylinder from the tunnel, and perhaps also occasionally as the ice plug pulsates back and forth in the cylinder. Large errors are eliminated by comparing duplicate side by side captures, but smaller errors can nevertheless persist and will always be in the direction of a lower indicated ICC IWC. In addition, the observation of ice depositing on the forward walls of the cylinder wall moving towards the mouth suggests the possibility of a continuous loss of captured ice that may not be identified in duplicate samples. Finally, sublimation of ice at the leading edge of the plug in a turbulent sub saturated volume near the stagnation temperature will reduce ice capture at a larger proportion at lower IWCs than higher IWCs, since the time of the lower IWC captures is proportionately longer, and the surface area of the leading edge of the ice plug is approximately constant.

In spite of these uncertainties, the comparison of the IKP2-1 to ICC IWC is reasonable, and generally within the original target of 20 percent accuracy for the IKP2. The ICC method shows promise in attaining higher levels of accuracy as an IWC reference, but needs further investigation and perhaps technical improvements to what this study has been able to achieve to date.

\section{Conclusions}

An isokinetic total water content evaporator was developed (Ref. 21) to make measurements at high speed, high altitude, and in high IWC conditions to collect data in deep tropical convective clouds to support assessment of the new Appendix D icing envelope. The design goal was 20 percent accuracy in TWC at an airspeed of $200 \mathrm{~ms}^{-1}$. This article describes the downsizing of the prototype instrument for use on an aircraft smaller than originally intended, and the performance and accuracy testing of that instrument to date. 
The prototype instrument (IKP1) was downsized to decrease weight by almost 50 percent, drag by 34 percent, power consumption by 44 percent, and wing wiring from 72 to 24 wires. The only significant compromise was the decrease of the inlet size from 10 to $7 \mathrm{~mm}$, necessary to meet the power consumption reduction. The new probe (IKP2-1) was ready for testing less than 6 months after project initiation, and underwent 4 separate wind tunnel investigations before the start of its first successful flight program in January 2014 on the CNRS Falcon-20 aircraft during the HAIC-HIWC campaign in Darwin, less than one year after project launch. Since then, it has been used successfully in 2 other flight programs and three more wind tunnel evaluations. A second copy (IKP2-2) of the second generation probe has been manufactured and was flown on the NRC Convair 580 and NASA DC-8, and supported testing in the NASA Propulsion Systems Lab and Icing Research Tunnel.

IKP2-1 underwent a series of performance tests before its first flight campaign. The probe was quickly found to saturate in very high IWC conditions, and the evaporator was redesigned and replaced. Subsequent wind tunnel testing at realistic airspeeds, altitudes, temperatures, and at IWCs in excess of $15 \mathrm{gm}^{-3}$, revealed no further saturation.

Deicing performance of the probe inlet was also successfully tested in conditions of about 80 to 90 percent of the $2.6 \mathrm{~nm}$ Appendix C intermittent maximum LWC $\left(2.8 \mathrm{gm}^{-3}\right)$. This was the highest value that could be practically tested in the wind tunnel for an extended period. The probe was exposed for a much longer distance than $2.6 \mathrm{~nm}$, equivalent to high altitude exposures of about 15 to $18 \mathrm{~nm}$, much longer than expected in natural conditions, and far in excess of what has been observed in the 3 flight campaigns to date. There remains a relatively large margin in de-icing power if it is deemed a requirement in the future.

The ability of the probe to adjust to isokinetic flow has been assessed in 3 flight programs. While the probe is able to successfully adjust to and maintain a desired flow through the automatic control of a flow-restricting butterfly valve, the ability of the probe to maintain isokinetic flow in flight mainly depends on whether there is sufficient flow margin to reach the isokinetic value. During flights tests, the flow margin was found to be similar to the wind tunnel results at low altitude, but dropped off significantly with height to about 4 percent at 40,000 ft $(12195 \mathrm{~m})$ pressure altitude In spite of the low flow margin at altitude, the valve typically controlled the flow to between 0.90 and 1.05 of isokinetic during flight campaigns. A small correction for TWC to account for flow variations for the typically ballistic ice particle mass is incorporated in the IKP2 TWC calculation (Ref. 10).

During the early comparisons of the IKP2-1 LWC to tunnel reference values, differences were unexpectedly high. A close inspection of the IKP2-1 tip revealed a somewhat blunt leading edge with some shape irregularity, leading to a perceived uncertainty of the effective inlet area. The tip was redesigned to incorporate a sharp leading edge bevel to deflect tip-impacting particles away from the inlet, and a well-defined defined circular inlet was machined to minimize sample area uncertainty. Subsequent comparisons with wind tunnel reference values improved significantly, although other changes may have also contributed to that improvement.

A fundamental requirement for IKP2 accuracy is that particles are evaporated before exiting the flow exhaust. A numerical study of the trajectory of hydrometeors (Ref. 24) concludes that particles larger than about $25 \mu \mathrm{m}$ will strike the hot evaporator wall, and those smaller have sufficient residence time to evaporate before the exhaust outlet. Some indirect evidence of complete particle evaporation comes from wind tunnel testing, where the IKP2-1 IWC remained linear with respect to ice delivery rate in realistic flight conditions at IWCs in excess of $15 \mathrm{gm}^{-3}$. The assumption here is that any particle flow-through might worsen as evaporator demand increased with IWC, resulting in an IKP2 IWC non-linearity with increased ice delivery.

The calculation of the IKP2 hydrometeor TWC requires the subtraction of an independently measured background water vapour (BWV) measurement. The accurate measurement of the BWV continues to be a surprisingly difficult problem that has varied according to LWC or IWC conditions, from wind tunnel to aircraft, and has been dependent in our experiments on a number of factors including air inlet design. In some conditions, particularly at warm temperatures, it is the dominant source of TWC error. The work is ongoing to develop the best methods for each application. In our wind tunnel experiments, the BWV did 
not change rapidly with time, and the various humidity devices could be periodically normalized to remove BWV offsets of up to several tenths of a $\mathrm{gm}^{-3}$ relative to the IKP2, minimizing the errors in the IKP2 TWC calculation. The source of these offsets was primarily the existence of different LICOR hygrometer instrument offsets. In addition, wind tunnel experiments have revealed that BWV may be affected by inlet ingestion of hydrometeors, and perhaps by evaporation/sublimation of hydrometeors in adiabatic temperature rises in partial stagnation regions induced by the inlet itself. In each wind tunnel test, the best inlet was identified and used if possible, or errors were estimated if not using the best inlet. Wind tunnel BWV measurements may rise in cloud in sub saturated conditions, or even lower in supersaturated conditions, the latter a situation not initially anticipated.

Some factors affecting BWV removal are more important for flight measurements. In the vicinity of deep tropical convective clouds, very large natural variations in humidity can be experienced, requiring very accurate synchronization and a compatible frequency response of the IKP2 and BWV measurements to avoid excessive noise in the zero-level out of cloud. At $-10{ }^{\circ} \mathrm{C}$ near Darwin, the ice saturation BWV is about $2.2 \mathrm{gm}^{-3}$, of the same order as the additional hydrometeor IWC to be separated from the IKP2 humidity signal. In practice, we have found that small errors in synchronization and frequency response practically limit IKP2 1-sec measurements in turbulent tropical conditions to temperatures colder than about $0{ }^{\circ} \mathrm{C}$, due to out-of-cloud baseline noise levels that reach several tenths of a $\mathrm{gm}^{-3}$ and worsen quickly for warmer temperatures. Fortunately, this effect decreases rapidly with decreasing temperature due to the exponential decrease in the saturation humidity values with decreasing temperature. Similar problems of inlet contamination by ice ingestion and sublimation in inlet-induced adiabatic temperature rises are at play on aircraft as well as wind tunnels. If it were not for these potential contaminating effects, a simple out-of-cloud adjustment for IKP2/BWV hygrometer offsets would suffice to ensure accurate IKP2 TWC calculation. But the existence of contamination has not yet been demonstrated conclusively, and is the subject of continuing study. An interim solution has been to assume ice saturation during incloud portions of flight, and estimate errors based on expected difference between ice and water saturation. For example, at $-10,-30$ and $-40{ }^{\circ} \mathrm{C}$, the differences are $0.22,0.11$ and $0.06 \mathrm{gm}^{-3}$, respectively for Darwin conditions. These errors assume accurate identification of an ice saturated region in cloud, or some other method of accurately removing the BWV offset. By $-50 \mathrm{C}$, the saturation BWV levels are very low $\left(0.04 \mathrm{gm}^{-3}\right)$ and TWC errors are accordingly small.

A field calibration cart was developed by SEA for laboratory and flight campaign IKP2 performance testing. It has also provided important information on IKP2 absolute LWC accuracy and calibration stability. The system provides a measured amount of water directly into the inlet of the IKP2 at a measured airspeed. The comparison provides an estimate in ground conditions of the combined LWC accuracy of all IKP2 component measurements and calculations with the exception of the inlet area measurement. Results indicate an agreement between the IKP2 and the calibration values of about \pm 4 percent over 2.5 years and 15 calibrations, with no noticeable trends with time or differences between the two IKP2s.

Careful LWC comparisons of IKP2-1 and IKP2-2 were made to NASA IRT reference values, the latter provided by hot-wire measurements that have been crossed checked against traditional icing blade measurements. The accuracy of the NASA IRT LWC reference values is estimated by NASA to be approximately 10 percent. Nominal test conditions varied from 77 to $128 \mathrm{~ms}^{-1}$ true airspeed, 15 to $196 \mu \mathrm{m} \mathrm{MVD}$, and 0.48 to $3.71 \mathrm{gm}^{-3}$. A linear regression of IKP2-2 and IKP2-1 measurements versus the tunnel calibration revealed that the IKP2 consistently measured about a factor 1.12 higher than the tunnel calibration with little bias. The precision of the IKP2-1 and IKP2-2 measurements, taken independently one day apart, was estimated at better than 1 percent. Since any differences between the two IKP2s also included day-to-day tunnel differences, this high IKP2 precision was also an indication of the high level of tunnel repeatability. In terms of overall accuracy, it was concluded that the IKP2 probes agreed in a highly correlated manner to the IRT reference values with a scale factor difference that was within the expected scale errors of the combined IKP2 and tunnel measurements. 
The search for an equally convincing absolute accuracy assessment in IWC conditions has proven elusive. A wind tunnel facility with an accurate IWC reference method capable of testing the IKP2 at high speed could not be found, leading the authors to pursue their own accuracy estimates. Measurements with the IKP2 in two different tunnels, one under conditions close to high altitude flight conditions, have shown a linear relationship of IWC versus ice delivery rate up to in excess of $15 \mathrm{gm}^{-3}$, revealing that there is no evidence of roll off in the response of the probe as IWC increases. In one of these tunnels, an independent bulk IWC estimate was obtained using ice capture cylinders, up to an IWC of approximately $4.4 \mathrm{gm}^{-3}$ at $150 \mathrm{~ms}^{-1}$. The ice capture cylinder (ICC) method has been first used in European tunnels, but there is little available published information. The authors discovered a number of difficulties in obtaining consistent ICC measurements, and the refinement of the method was a learning process and specific to the tunnel. The results presented in this article from the Jan. 2016 tests represent our best comparisons to date with the best ICC data quality control, but there is likely still room for improvement. The authors believe that the most significant errors in the ICC IWC estimate all tend towards underestimation, particularly for the lowest IWC collections. Visual records of ice collection using transparent cylinders suggested several possible avenues though which collected ice may have been re-entrained out the cylinder or partially sublimated during collection. Comparisons of IKP2-1 to ICC IWC estimates, all taken near $150 \mathrm{~ms}^{-1}$, reveal that the IKP2-1 consistently measured higher than the ICC. The ratios of IKP2-1 to ICC IWC were 1.30 at $0.7 \mathrm{gm}^{-3}, 1.09$ at $2.46 \mathrm{gm}^{-3}$, and 1.15 at $4.4 \mathrm{gm}^{-3}$, with an overall average ratio of 1.20 . These higher ratios at lower TWC were not observed in the careful NASA IRT comparisons in LWC conditions. The authors believe that lower ICC measurements are likely due to disproportionate ICC errors at low IWC due to collection loss and/or sublimation. Furthermore, there is some indirect evidence that the IKP2-1 IWC is the more the credible measurement at low IWC, in comparisons of the IKP2 and ICC IWCs versus ice delivery rate. Further development of an IWC reference standard and assessment of uncertainty is recommended.

In summary, IKP2 system accuracy has been estimated in a companion article to be approximately 3 to 5 percent for TWC greater than $0.5 \mathrm{gm}^{-3}$ and temperatures colder than $-29{ }^{\circ} \mathrm{C}$ (Ref. 10). The same analysis shows than the target accuracy of 20 percent is exceeded for all conditions colder than $-10{ }^{\circ} \mathrm{C}$ and greater than about $0.25 \mathrm{gm}^{-3}$. The present study found that IKP2 LWC measurements were within about 4 percent of an SEA designed field calibration system, and about 12 percent higher than the NASA IRT reference LWC, whose accuracy is estimated by NASA at 10 percent. IKP2 IWC measurements were on the average 20 percent higher than ice capture cylinder measurements. It is believed that this is not an indication of over-reading of the IKP2, but rather, at least in part, a result of shortcomings in the ice capture cylinder method as applied in this study, which is exploratory and with uncertainties that tend to lead to underestimation. Nevertheless, the comparisons of are still just within the original 20 percent accuracy target for the IKP2. Future work will include NIST calibrations of the LICOR-840A hygrometers used by the IKP2 and the BWV measurements spanning flight atmospheric pressures, and analyses of additional flight data from the HAIC-HIWC Cayenne 2015 and HIWC RADAR 2015 flight campaigns, which are expected to provide additional information on the effect of BWV uncertainty on flight campaign TWC estimates.

\section{References}

1. Lawson, R.P., Angus, L.J., and Heymsfield, A.J., "Cloud Particle Measurements in Thunderstorm Anvils and Possible Threat to Aviation," J. Aircraft, 35, no. 1, 1998, pp. 113-121.

2. Mason, J.G., Strapp, J.W. and Chow, P., "The Ice Particle Threat to Engines in Flight," 44th AIAA Aerospace Sciences Meeting, Reno, Nevada, 9-12 January 2006, AIAA-2006-206.

3. Mazzawy, R.S. and Strapp, J.W., "Appendix D - An Interim Icing Envelope: High Ice Crystal Concentrations and Glaciated Conditions," SAE Transactions, Journal of Aerospace, vol. 116, 2007, pp. 634-642.

4. McNaughtan, I.I., "The Analysis of Measurements of Free Ice and Ice/Water Concentrations in the Atmosphere of the Equatorial Zone," R.A.E. Technical Note No. Mech. Eng. 283. 1959. 17 pps. 
5. FAA, Docket No. FAA-2010-0636; Amendment Nos. 25-140 and 33-34, "Airplane and Engine Certification Requirements in Supercooled Large Drop, Mixed Phase, and Ice Crystal Icing Conditions," Federal Register, vol.79, no 213, 4 Nov. 2014.

6. European Aviation Safety Agency "Certification Specifications and Acceptable Means of Compliance for Large Aeroplanes, CS-25," Amendment 16, 12 Mar. 2015. https://www.easa.europa.eu/documentlibrary/certification-specifications/cs-25-amendment-16

7. Duviver, E., 2010: "High Altitude Icing Environment," Intl. Air Safety and Climate Change Conf., 8-9 Sep. 2010, Cologne, Germany, available from https://

www.easa.europa.eu/conferences/iascc/doc/Workshop\%201\%20Presentations/Workshop1_DAY\%202 /1_Duvivier_EASA/IASCC_E\%20Duvivier.pdf

8. Strapp, J.W., Korolev, A., Ratvasky, T.P, Potts, R., Protat, A., May, P., Ackerman, A., Fridlind, A., Minnis, P., Haggerty, J., Riley, T.J., Lilie, L.E., and Isaac G. A., "The High Ice Water Content (HIWC) Study of Deep Convective Clouds: Science and Technical Plan," FAA report DOT/FAA/TC 14/31, 2016, in press.

9. Dezitter, F., Grandin, A., Brenguier, J-L, Hervy, F., Schlager, H., Villedieu, P., and Zalamansky, G., "HAIC - High Altitude Ice Crystals," 5th AIAA Atmospheric and Space Environments Conference. American Institute of Aeronautics and Astronautics. 2013, Doi: 10.2514/6.2013-2674.

10. Davison, C., Strapp, J.W., Lilie, L.E., Ratvasky, T.P, and Dumont, C., "Isokinetic TWC Evaporator Probe: Calculations and Systemic Error Analysis," 8th AIAA Atmospheric and Space Environments Conference, 13-17 June 2016, Washington, D.C., AIAA-2016-4060, NASA/TM-2016-219150.

11. Heymsfield, A.J., Schmitt, C., Bansemer, A., and Twohy, C.H., "Improved Representation of Ice Particle Masses Based on Observations in Natural Clouds," J. Atmos. Sci., 67, 2010, pp. 3303-3318, doi:10.1175/2010JAS3507.1.

12. Korolev, A.V., Strapp, J.W., Isaac, G.A., and Nevzorov, A.N., "The Nevzorov Airborne Hot-wire LWC-TWC Probe: Principle of operation and Performance Characteristics," J. Atmos. Oceanic Technol., vol. 15, no. 6, 1998, pp. 1495-1510.

13. Emery, E., Miller, D., Plaskon, S., Strapp, J.W., and Lilie, L.E., "Ice Particle Impact on Cloud Water Content Instrumentation," 42 $2^{\text {nd }}$ AIAA Aerospace Sciences Meeting and Exhibit, Jan. 2004, AIAA-2004-0731.

14. Strapp, J.W., Lilie, L.E., Emery, E.E., and Miller, D.R., "Preliminary Comparison of Ice Water Content as Measured by Hot Wire Instruments of Varying Configuration," 43rd Aerospace Sciences Meeting and Exhibit, Reno, Nevada, 11-13 January 2005, AIAA-2005-0860.

15. Korolev, A.V., Strapp, J.W., Isaac, G.A., and Emery, E., "Improved Airborne Hot-Wire Measurements of Ice Water Content in Clouds," 15th International Conference on Clouds and Precipitation, 7-13 July 2008, Cancun, Mexico, P13.4.

16. Strapp, J.W., MacLeod, J., and Lilie, L.E., "Calibration of Ice Water Content in a Wind Tunnel / Engine Test Cell Facility," $15^{\text {th }}$ International Conference On Clouds and Precipitation, 7-11 July 2008, Cancun, Mexico.

17. Grandin, A., Merle, J-M, Weber, M., Strapp, J.W., Protat, A., and King, P., "AIRBUS Flight Tests in High Ice Water Content Regions," 6th American Institute of Aeronautics and Astronautics (AIAA) Atmospheric and Space Environments Conference, Atlanta, GA, 16-20 June 2014.

18. Weinstock, E.M., Smith, J.B., Sayres, D., Spackman, J.R., Pittman, J.V., Allen, N., Demusz, J., Greenberg, M., Rivero, M., Solomon, L., and Anderson, J.G., "Measurements of the Total Water Content of Cirrus Clouds. Part I: Instrument Details and Calibration," J. Atmos. Oceanic Technol., 23, 2006, pp. 1397-1409.

19. Davis, S.M., Hallar, A.G., Avallone, L.M., and Engblom, W., "Measurement of Total Water With a Tunable Diode Laser Hygrometer: Inlet Analysis, Calibration Procedure, and Ice Water Content Determination," J. Atmos. and Oceanic Technol., 24, 2007, pp. 463-475.

20. Twohy, C.H., Schanot, A.J. and Cooper, W.A. "Measurement of Condensed Water Content in Liquid and Ice Clouds using an Airborne Counterflow Virtual Impactor," J. Atmos. Oceanic Technol., 1997, 14, pp. 197-202. 
21. Davison, C.R., MacLeod, J.D., Strapp, J.W., and Buttsworth, D.R., "Isokinetic Total Water Content Probe in a Naturally Aspirating Configuration: Initial Aerodynamic Design and Testing," 46th AIAA Aerospace Sciences Meeting and Exhibit, Jan. 10, 2008, Reno, Nevada, AIAA-2008-0435.

22. Davison, C.R., MacLeod, J.D., and Strapp, J.W., "Naturally Aspirating Isokinetic Total Water Content Probe: Evaporator Design and Testing," 1st AIAA Atmospheric and Space Environments Conference, 25 June 2009, San Antonio, Texas, AIAA-2009-3861.

23. Davison, C.R., Landreville, C., and MacLeod, J.D., "Initial Development and Testing of Isokinetic Probe to Measure Total Water Content During Ground and Airborne Testing," NRC, LTR-GTL-20100002, Ottawa, Mar. 2010.

24. Davison, C.R., MacLeod, J.D., and Ratvasky, T.P., "Naturally Aspirating Isokinetic Total Water Content Probe: Preliminary Test Results and Design Modifications," 2nd AIAA Atmospheric and Space Environments Conference, 2-5 August 2010, Toronto, Ontario, AIAA-2010-7530.

25. Davison, C.R., Ratvasky, T.P., and Lilie, L.E., "Naturally Aspirating Isokinetic Total Water Content Probe: Wind Tunnel Test Results and Design Modifications," SAE 2011 International Conference on Aircraft and Engine Icing and Ground Deicing, 13-17 June 2011, Chicago, Illinois, SAE 2011-380036.

26. Al-Khalil, K., Irani, E., and Miller, D., "Mixed-Phase Icing Simulation and Testing at the Cox Icing Wind Tunnel," 41st AIAA Aerospace Sciences Meeting and Exhibit, Jan. 2003, AIAA-2003-0903.

27. Van Zante, J.F., Ide, R.F, Steen, L.E. and Acosta, W.J., "NASA Glenn Icing Research Tunnel: 2014 Cloud Calibration Procedure and Results," NASA Technical Report NASA/TM-2014-218392, 2014, $18 \mathrm{pp}$.

28. Fuleki, Dan, Chalmers, J.L.Y, and Galeote, B., "Technique for Ice Crystal Particle Size Measurements and Results for the National Research Council of Canada Altitude Ice Crystal Test System," Society of Automotive Engineers, 2015. SAE 2015-01-2125.

29. Knezevici, D., Fuleki, D.M., and MacLeod, J.D., "Development and Commissioning of a Linear Compressor Cascade Rig for Ice Crystal Research, SAE 2011 International Conference on Aircraft and Engine Icing and Ground Deicing, 13-17 June 2011, Chicago, Illinois, SAE 2011-38-0079, 2011, doi:10.4271/2011-38-0079.

30. Leroy, D., Fontaine, E., Schwarzenboeck, A., Strapp, J.W., Lilie, L.E., Delanoe, J., Protat, A., Dezitter, F., and Grandin, A., "HAIC/HIWC Field Campaign - Specific Findings on PSD Microphysics in High IWC Regions from In Situ Measurements: Median Mass Diameters, Particle Size Distribution Characteristics and Ice Crystal Shapes," SAE 2015 Int. Conf. on Icing of Aircraft, Engines, and Structures, 22-25 June 2015 Prague, the Czech Republic. SAE 2015-01-2087.

31. Title 14 Code of Federal Regulations, Aeronautics and Space, Part 25 Airworthiness Standards: Transport Category Airplanes, Section C25.1: Appendix C; published by the Office of the Federal Register, National Archives and Records Administration, Washington, DC., Amdt. 25-140, effective 5Jan-2015. http://rgl.faa.gov/Regulatory_and_Guidance_Library\%5CrgFAR.nsf /0/944A817E0D942A3486257DC700571818.

32. Korolev. A., and Isaac, G.A., "Relative Humidity in Liquid, Mixed-Phase, and Ice Clouds," J. Atmos. Sci., Vol. 63, 2006, pp. 2865-2880.

33. King, W.D., "Airflow and Particle Trajectories around Aircraft Fuselages. I: Theory," J. Atmos. Oceanic Technol., vol. 1, 1984, pp. 5-13.

34. Diskin, G.S., Podolske, J.R., Sachse, G.W.,. and Slate, T.A., "Open-path Airborne Tunable Diode Laser Hygrometer," in Diode Lasers and Applications in Atmospheric Sensing, Alan Fried, Editors, Proceedings of SPIE vol. 4817, SPIE, Bellingham, WA, 2002, pp. 196-204.

35. Steen, L.E., Ide, R.F., and Van Zante, J.F., and Acosta, W.J., "NASA Glenn Icing Research Tunnel: 2014 and 2015 Cloud Calibration Procedures and Results," NASA/TM-2015-218758, 2015, 26 pp.

36. Steen, L.E., Ide, R.F., and Van Zante, J.F., "An Assessment of the Icing Blade and the SEA MultiElement Sensor for Liquid Water Content Calibration of the NASA GRC Icing Research Tunnel," 8th AIAA Atmospheric and Space Environments Conference, 13-17 June 2016, Washington, D.C., submitted for publication. 


